\title{
A Prognostic Phenology Scheme for Global Terrestrial Carbon Cycle Models
}

\author{
Jörg Kaduk and Martin Heimann \\ Max-Planck-Institute for Meteorology, \\ Bundesstr. 55, 20146 Hamburg, Germany \\ As accepted by Climate Research
}

\begin{abstract}
Prognostic and mechanistic schemes for the determination of plant phenological stages from environmental conditions and the estimation of net primary production (NPP) are presented. The new schemes account for different biomes and are included in a global model of carbon cycling in the terrestrial biosphere. The capability of such a model to simulate the seasonal cycle of atmospheric $\mathrm{CO}_{2}$ is explored. The model is forced by mean monthly climate variables (temperature, precipitation and light) and the mean annual $\mathrm{CO}_{2}$-concentration. It predicts the atmosphere-biosphere $\mathrm{CO}_{2}$ exchange fluxes, leaf area index (LAI), and the times of budburst and leaf abcission. The predicted variables offer means of validation against data of the observed annual cycle of atmospheric $\mathrm{CO}_{2}-$ concentration and observations of LAI derived from satellite data. Estimated annual NPP of forests appears realistic, however NPP of grass dominated biomes is greatly underestimated. This seems to be related to the fact that belowground biomass is not explicitly considered in the model. The results of a simulation of the seasonal cycle of of atmospheric $\mathrm{CO}_{2}$-concentration using a three dimensional atmospheric transport model are in satisfying agreement with the observations.
\end{abstract}

\section{Introduction}

The terrestrial biosphere represents a major compartment in the global carbon cycle with gross exchange fluxes of $40-80 \mathrm{GtC}$ per year $\left(1 \mathrm{GtC}=10^{12} \mathrm{~kg}\right.$ Carbon) (Lieth 1975) which is about fifty percent of the gross exchanges of the atmosphere with all global carbon pools. Terrestrial vegetation alone accounts for $\approx 99 \%$ of the carbon in the living terrestrial biosphere (Whittaker and Likens 1973). Anthropogenic activities such as de- and afforestation, agricultural practices and burning of wood and fossil fuels interact significantly with the natural carbon cycling in the terrestrial vegetation. Therefore, land vegetation models describing the cycling of carbon through global land vegetation, plant litter, and soil organic carbon (SOC) the biospheric carbon cycle - can aid to evaluate scenarios of future management of agriculture and forestry - possibly under a climate change scenario as well.

The simulation of consequences of climate change scenarios requires models which are based on plant physiology rather than on correlational methods. Correlations derived from contemporary data relating for example net primary productivity to climate (e.g. the MIAMI model, Lieth 1975) are valid for the present assumed equilibrium state of climate and vegetation only. They cannot faithfully describe transient changes of vegetation caused by climate variations. In particular it is essential to simulate length and timing of the vegetation period on the basis 
of plant physiological principles. The reliable estimation of these two aspects of the seasonal climate and local vegetation is even more important in the case of an envisaged application of biosphere models within climate change scenario calculations. For example, although increased summer temperatures might have no direct effect, warming of winter temperatures might lead to a delayed budburst of temperate trees since these require a winter chilling period with temperatures below ca. $5^{\circ} \mathrm{C}$ for rapid budburst in the following spring (Murray et al. 1989).

Mechanistic descriptions of plant phenology with prognostic power, which can be assumed to be valid under changed climate and different atmospheric $\mathrm{CO}_{2}$ partial pressures as well, are only recently being developed. They still suffer from the uncomplete understanding and the complexity of several plant physiological processes, for example the regulation of growth processes by plants (Wardlaw 1990).

The main objective of the current work is to assess the simulation of the seasonal carbon dynamics of global vegetation employing a set of climate dependent physiologically based rules for phenological sequences. Here we model two phenological stages, namely budburst and leaf fall, on the basis of climate dependent biome specific rules -however not considering direct light effects.

For such an assessment we had to include the phenological scheme in a global biosphere model.

Several global biosphere models for the simulation of carbon exchange fluxes have been developed in the past. Their spatial resolutions range from few boxes representing the global biospheric carbon pools to about $0.5^{\circ} \times 0.5^{\circ}$ pixels, as e.g. the Terrestrial Ecosystem Model, TEM (Raich et al. 1991) and the High Resolution Biosphere Model, HRBM (Esser 1991, Esser et al. 1994). The modelling approaches comprise the employment of relations derived from regression analyses (HRBM), remote sensing data (e.g. Heimann and Keeling 1989, Knorr and Heimann 1995), and the application of plant physiological relations (TEM, the Frankfurt Biosphere Model, FBM (Janecek et al. 1989, Lüdeke et al. 1995)).

The structure of our global model is based on the HRBM since it provides a more appropriate structure of biospheric carbon (two pools of "living" and three pools of "dead" carbon) for the study of the biospheric carbon cycle than the FBM (two pools of "living" and one pool of "dead" carbon) or TEM (one pool each). Two pools of "living" carbon (woody, herbaceous) are a minimal structural prerequisite for a realistic consideration of the effects of climate and $\mathrm{CO}_{2}$ on the carbon partioning in the living biosphere. Several carbon pools are needed to describe the different turnover times of the various components in the "dead" organic carbon.

The HRBM relies for the estimation of annual net primary productivity (NPP) essentially on the correlational MIAMI model -which relates annual NPP to mean annual temperature and annual precipitation (Lieth 1975). The seasonal distribution of annual NPP and litter production (i.e. the determination of phenology and seasonal NPP) is accomplished by employing satellite data. These approaches cast some doubt on the suitability of the HRBM for prognostic model simulations.

We therefore designed two submodules which replace the correlational approach of estimating NPP and the satellite data based scheme for the temporal distribution of annual NPP and litter production with mechanistic physiologically based formulations.

Our general approach to determine NPP is based on the scheme applied in the gap model FORSKA for the simulation of patch-scale forest dynamics. It predicts NPP for each plant of the patch with an annual time step. The environmental effects (temperature, moisture deficit and $\mathrm{CO}_{2}$ ) are incorporated by annually averaged scalar multipliers calculated on a daily basis. Nutrient limitations are neglected. However, there are some major modifications in the explicit 
formulation of our NPP-module as compared to FORSKA. In particular, unlike as in FORSKA, in our model NPP is determined on a quasi daily basis from gross primary productivity (GPP) and plant respiration which are modelled separately. Furthermore FORSKA does not predict phenology on a seasonal basis as our model. In addition, in our model there is a coupling between NPP and phenology during the time course of the year which has no parallel in FORSKA. Finally -as important simplification- in our model NPP it is not simulated on a per plant basis but rather on a grid element basis assuming a homogeneous canopy within each gridelement.

The NPP simulation requires the specification of radiation and actual as well as potential evapotranspiration (AET and PET respectively)). Therefore we retained from FORSKA main parts of the radiation and hydrology simulation schemes. These are based on a simple soil water bucket model neglecting vertical structure and vegetation-hydrology interactions.

We consider potential natural vegetation only, assuming a distribution of potential vegetation classified in 17 biomes as emerging from the BIOME I model by Prentice et al. (1992).

Thus, the complete model described here is based on the BIOME I vegetation map and consists of the radiation and soil water bucket models from FORSKA, the two newly developed mechanistic modules and the scheme for heterotrophic respiration (litter decay) of the HRBM. Hereafter, "new model" denotes this specific setup of modules.

The simulation of NPP is based on a mechanistic understanding of plant physiology. Although phenology is derived using a correlational approach we believe that the resulting formulation reflects specific physiological relations and might be called mechanistic as well. We assume that it is valid independent of the climate and satellite data used for its derivation. Heterotrophic respiration relies on correlations with temperature and precipitation as derived by Esser et al. (1982). The water balance model is in so far not mechanistic as it does not include a mechanistic approach for the simulation of plant water-uptake.

The newly developed NPP module includes an assimilate pool which represents the starch stored within plants for respiration and budburst in the next growing season (Waring and Schlesinger 1985). This pool is included for a more realistic simulation of respirational processes and the storage of reserves in plants in particular during the dormant season. Its introduction offers the possibility to address the following two processes: (1) Effects of changes in the growing season: For example, a prolonged summer drought might lead to a negative annual balance of GPP and plant respiration, hence negetive annual NPP. The HRBM in contrast would always predict non-negative annual NPP. (2) Modifications of the plant development by the amount of assimilates remaining from the previous growing season. Since plant shooting at the beginning of a growing season can only occur if sufficient assimilates remained from the previous growing season this introduces a dependence of the development of vegetation in the current growing season on the production conditions in the previous years. There is no such connection with previous seasons in the HRBM, where NPP is directly determined from the climate of the current year. Both processes might be important during transient climate variations, when vegetation is subjected to conditions to which it is only poorly adapted. In contrast, the HRBM would always predict the NPP of a vegetation well adapted to the prevailing climate.

The soil water module is included because the growing potential of vegetation is determined by the seasonal characteristics of soil moisture and not so much by annual precipitation as assumed in the HRBM. An appropriate simulation of the seasonal time course of soil moisture is even more important for climate change scenarios since not necessarily its annual mean but its temporal distribution might change (Mitchell et al. 1990). The ratio of AET to PET as determined from the soil water module is used to simulate the effect of drought on assimilation. 
In the next section we describe the components of the new model. In section three we present the results of an equilibrium run of the new model and discuss these. Since NPP determines the carbon input into the biosphere its realistic simulation is essential and we discuss the power of our model to predict NPP in some length. As a first main validation exercise with the new biosphere model we focus on the simulation of the annual cycle of the atmospheric $\mathrm{CO}_{2}-$ concentration. Monthly net biospheric $\mathrm{CO}_{2}$ fluxes were determined from the biosphere model. These were transferred into the atmospheric transport model TM2 (Heimann and Keeling 1989, Heimann 1995). We then compare the resulting time evolution of the atmospheric $\mathrm{CO}_{2}-$ concentration with observed seasonal cycles of the measured atmospheric $\mathrm{CO}_{2}$-concentration.

\section{Model characteristics}

The framework of the global prognostic model for land vegetation presented here is based on the HRBM by Esser (1991). Spatial resolution of the HRBM is $0.5^{\circ}$ and the time resolution one month. The HRBM comprises in each model grid pixel six carbon pools -agricultural, natural herbaceous and woody living biomass, herbaceous and woody plant litter, and SOC. The model relies for the estimation of annual NPP on the correlational approach of the MIAMI model. In the HRBM annual NPP is further influenced by empirical soil factors and the atmospheric $\mathrm{CO}_{2}$-concentration. Litter production rates are derived from an empirical relation of NPP and biomass using the steady state assumption that the annual litter production equals annual NPP. The seasonal distribution of NPP and litter production is estimated from satellite measurements of the Normalized Difference Vegetation Index (NDVI). Litter and SOC decay rates are derived from direct measurements (Esser et al. 1982). The NPP model and in part the litter production scheme of the HRBM are replaced in our new model by two new modules described below.

Our approach to determine NPP follows in part FORSKA (Prentice et al. 1993). The biome distribution assumed in the new model is as resulting from by the BIOME I model by Prentice et al. (1992). The chosen biomes and their phenology type in the new model are given in Table 1. Deciduous biomes are those where all herbaceous biomass is shed once a year in a short period of time. In evergreen biomes the production rate for herbaceous litter is constant throughout the year. Mixed biomes are assumed to consist to $50 \%$ of deciduous and to $50 \%$ of evergreen plant types. The $17^{\text {th }}$ biome of Prentice et al. (1992) is called ice/polar desert, where we assume no flora.

Since we do not focus in the current work on climate or $\mathrm{CO}_{2}$-variations we do not make any specific distinctions concerning the major photosynthetic pathways $\left(\mathrm{C}_{3}, \mathrm{C}_{4}\right.$ and $\left.\mathrm{CAM}\right)$.

In addition to the forcing data of the HRBM (monthly mean temperature, monthly precipitation, mean annual atmospheric $\mathrm{CO}_{2}$-concentration) the new model requires monthly mean fraction of full sunlight of daylight hours.

In addition to the prognostic variables of the HRBM the new model predicts carbon storage in the assimilate pool and the time of budburst and leaf abcission. Furthermore, the simple radiation and soil modules simulate the hydrological variables soil water, runoff and actual and potential evapotranspiration prognostically. Since we consider potential natural vegetation only, the new model does not predict agricultural biomass as the HRBM.

The structure of the part of the new model which describes living vegetation is depicted in Fig. 1. In each grid cell there are three pools of living biomass (assimilate, herbaceous biomass (leaves and fine roots) and woody biomass (stem, branches and coarse roots)). GPP, the input into the assimilate pool, is calculated from temperature, AET/PET, $\mathrm{CO}_{2}$, and light. Plant respiration, being temperature dependent, depletes the assimilate pool. Vegetation state and the climate variables determine the allocation of the assimilates to herbaceous and woody 


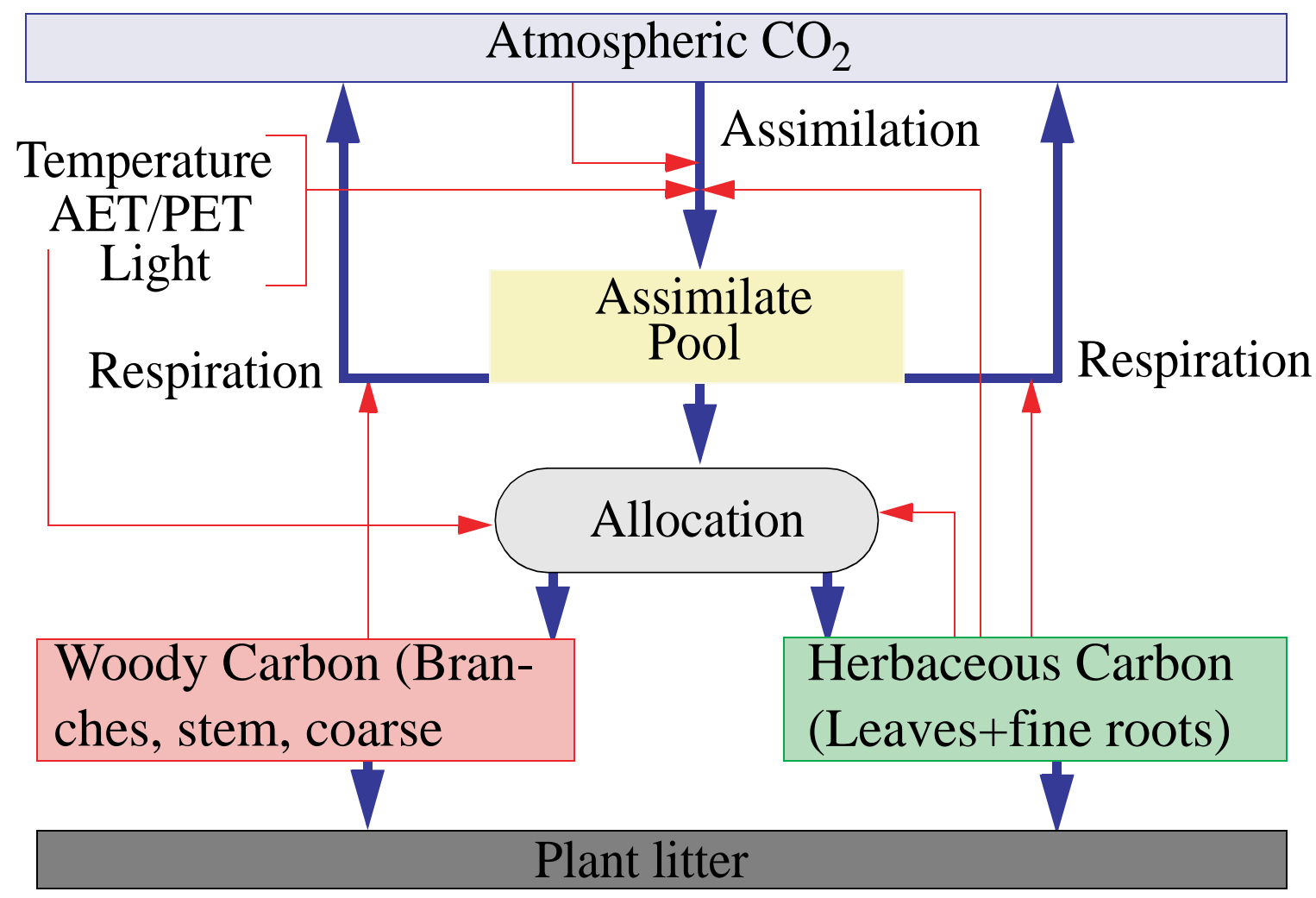

Figure 1: Structure of the part of the new model of the biospheric carbon cycle which describes living vegetation for each grid cell.

biomass.

The model considers in each grid cell three pools of vegetation debris: herbaceous and woody litter and SOC. Litter and SOC production rates depend on vegetation type and the climate variables. Litter and SOC decay rates are determined from the climate variables only.

Thus in total the new model consists of six carbon state variables (assimilate, herbaceous and woody "living carbon", herbaceous and woody litter and soil organic carbon).

Formally is the carbon part of the model a linear inhomogeneous system of six ordinary differential equations of first order. The inhomogeneity is given by the NPP calculated as described in section 2.3 and the coefficients by the transfer rates defined in sections 2.4 and 2.5 .

Radiation and soil water simulations follow in principle the description in Prentice et al. (1993). We mention the most important points briefly.

\subsection{Radiation}

Instantaneous downward short wave radiation is modelled according Linacre (1968) by:

$$
R_{s, n d}(t)=\left(c_{1}+d_{1} S_{n d}\right)(1-\beta) Q_{0} \cos \left(\zeta_{n d}\left(t_{\pi}\right)\right) ;
$$

$c_{1}, d_{1}$ are empirical constants $\left(c_{1}=0.25, d_{1}=0.5\right), S_{n d}$ the fraction of sunny time of the daylight hours, nd the day of the year $(\mathrm{nd}=1, \ldots, 360$, i.e. we simulate a year with 360 days $), \beta$ the short wave albedo, and $t_{\pi}$ the time of the day. $Q_{0}$ and $\cos \left(\zeta_{n d}\left(t_{\pi}\right)\right)$ are given by:

$$
\begin{aligned}
& Q_{0}=Q_{00}\left(1+0.0335 \cos \left(\frac{n d}{360} \cdot 2 \pi\right)\right) \\
& \cos \left(\zeta_{n d}\left(t_{\pi}\right)\right)=\sin (l a t) \sin (\delta)+\cos (l a t) \cos (\delta) \cos \left(t_{\pi}\right),
\end{aligned}
$$


where $Q_{00}$ is the solar constant $\left(1360 \mathrm{Wm}^{-2}\right)$, lat the latitude, and:

$$
\delta_{n d}=\frac{-23.4^{\circ}}{360^{\circ}} 2 \pi \cdot \cos \left(\frac{n d+10}{360} \cdot 2 \pi\right) .
$$

The time of the day, $t_{\pi}$, is measured in angular units from solar noon.

The outgoing long wave radiation, $R_{l}$, is estimated according Linacre (1968) by:

$$
R_{l, n d}=\left(b_{1}+\left(1-b_{1}\right) S_{n d}\right)\left(a_{1}-T_{n d}\right),
$$

where $a_{1}, b_{1}$ are again empirical constants $\left(a_{1}=107, b_{1}=0.2\right), T_{n d}$ the mean daily temperature in degrees Celsius. The diurnal cycle of temperature is neglected. Thus $R_{l, n d}$ is constant during the day.

Net radiation, $R_{n, n d}(t)$, is defined as the difference of $R_{s, n d}(t)$ and $R_{l, n d}$. Daily net radiation results from an integration of $R_{n, n d}(t)$ from sunrise to sunset.

Photosynthetically active radiation (PAR) is assumed to be the frequency band of $400-$ $700 \mathrm{~nm}$. This band is approximated by $50 \%$ of the short wave radiation. The mean photondensity of this frequency-band is $\approx 4.6 \mu E J^{-1}$ (Landsberg 1986). Thus downward not reflected PAR at time $t$ at the top of canopy in $\left[\mu \mathrm{Em}^{-2} s^{-1}\right], I_{0, n d}(t)$, is given by:

$$
I_{0, n d}(t)=\frac{0.5}{e^{*}} R_{s, n d}(t)
$$

$\left(e^{*}=0.22 M J E^{-1}\right)$. Extinction of PAR in the Canopy is simulated according to the BeerLambert-law (Monsi and Saeki 1953):

$$
I_{n d}(z, t)=I_{n d}\left(H_{n d}, t\right) \cdot \exp \left(-k \cdot s_{L, n d}(z)\left(H_{n d}-z\right)\right) .
$$

where $\mathrm{z}$ is height above ground, $H_{n d}$ the stand height, $\mathrm{k}$ the light extinction coefficient, and $s_{L, n d}(z)$ the leaf density at height $\mathrm{z}$ (Fig. 2). Thus, $I_{n d}\left(H_{n d}, t\right) \equiv I_{0, n d}(t)$ and plant absorbed PAR at height $\mathrm{z}$ and time $\mathrm{t}, I_{a b, n d}(z, t)$, results from:

$$
I_{a b, n d}(z, t)=\frac{d I}{d z}(z, t)=k s_{L, n d} I_{0, n d}(t) \cdot e^{-k s_{L, n d}\left(H_{n d}-z\right)}
$$

$H_{n d}$ depends on the amount of living woody biomass on the day nd (see 2.3.2). For the sake of simplicity the leaves are assumed to be evenly distributed throughout the canopy and $s_{L, n d}(z)$ to be constant with height, $s_{L, n d}(z) \equiv s_{L, n d} . s_{L, n d}$ results from the "reduced" specific leaf area $S L A^{*}$ (taking belowground biomass into account) and herbaceous biomass, $p h_{n d}$, on the day nd:

$$
s_{L, n d}=\frac{L A I_{n d}}{H_{n d}-B_{n d}}=\frac{S L A^{*} p h_{n d}}{H_{n d}-B_{n d}} .
$$

where $L A I_{n d}$ is leaf area index $\left[\mathrm{m}^{2} \mathrm{~m}^{-2}\right]$, and $B_{n d}$ bole height on the day nd. (Note that LAI is thus linearly related to the model state variable ph.)

Hereafter we drop the argument nd of all model quantities. For a complete list of the model quantities refer to the appendix.

\subsection{The soil water model}

From soil water, soil water capacity and daily net radiation (see previous section) we estimated AET and PET as in Prentice et al. (1993), following an approach of Jarvis and MacNaughton 
(1986). PET is linearly related to net radiation. AET is the minimum of PET and a linear function of actual soil water.

Jarvis and MacNaughton (1986) argue that if soil moisture is not limiting the large-scale evapotranspiration is determined mainly by the energy supply. Thus for simplicity we do not consider roots in detail but only the maximal plant available soil water and fixed matric potentials for the field capacity and the wilting point, which are necessary parameters for the bucket model.

We derived a global spatial distribution of maximal plant available soil water (soil water capacity between field capacity and wilting point) from the soil texture and depth data of Webb et al. (1992). This was achieved by applying regressions relating soil texture to soil hydraulic properties (from Cosby et al. 1984) assuming a root depth of $1 \mathrm{~m}$ if the depth data did not indicate shallower soil. Furthermore we applied globally uniform fixed potentials for field capacity of $100 \mathrm{hPa}$ and the permanent wilting point of $4500 \mathrm{hPa}$. These values seem appropriate for general applications (Lerch 1991, Prentice et al. 1992).

\subsection{The NPP module}

For the NPP module we retained from FORSKA the general approach. However we simulate gross primary production (GPP) and plant respiration (R) separately. Furthermore we employ the Arrhenius relationship for the temperature dependence of plant respiration instead of a $\mathrm{Q}_{10}$ formulation. The canopy is assumed to be homogeneous in the grid element. GPP and R are calculated by an integration through the vegetation canopy including a shade adaption of photosynthesis and respiration rates. Unlike as in FORSKA we determine NPP each time step (six days in the present model layout) which is important for our new phenology and allocation schemes.

During drought or in the dormant seasons NPP=GPP-R may become negative. All carbon necessary for growth processes is supplied from the assimilate pool. This setup allows for a strong dynamic response of plants to good growing conditions as the assimilates can be used for rapid growth.

The basic time step for the NPP submodule is one day. Plant structure is viewed idealized as in Fig. 2.

Instantaneous light dependent GPP (assimilation), A(z,t), and maintenance respiration, $\operatorname{Rt}(\mathrm{z})$, of leaves and wood are determined for each height $\mathrm{z}$ in the canopy and at every time $\mathrm{t}$ of the day assuming a reference climate condition. These instantaneous rates are integrated through the canopy and over the day to give standard daily rates, GPP $P_{s t d}$ and $R_{s t d}$ respectively, which are finally multiplied by factors representing the actual prevailing climate.

$G P P_{s t d}$ is multiplied by two factors, $\Phi_{T} \equiv \Phi_{T}(T)$, and $\Phi_{D} \equiv \Phi_{D}(A E T, P E T)$ representing the negative influences of non-optimal temperature and limiting soil moisture on photosynthesis, respectively. $\Phi_{T}$ and $\Phi_{D}$ vary between zero and one. $R_{s t d}$ is modified by a temperature dependent respiration factor, $\mu_{T} \equiv \mu_{T}(T)$.

Thus daily NPP, $N P P_{d}$, is given by:

$$
N P P_{d}=\Phi_{T} \Phi_{D} \cdot G P P_{s t d}-\mu_{T} \cdot R_{s t d}
$$

The influence of the atmospheric $\mathrm{CO}_{2}$-concentration on photosynthesis is simulated by a growth factor, $\Phi_{C} \equiv \Phi_{C}\left(C O_{2}\right)$, modifying the maximal assimilation rate. This influence is accounted for in the formulation of $\mathrm{A}(\mathrm{z}, \mathrm{t})$.

The explicit equations are given in the following subsections. 


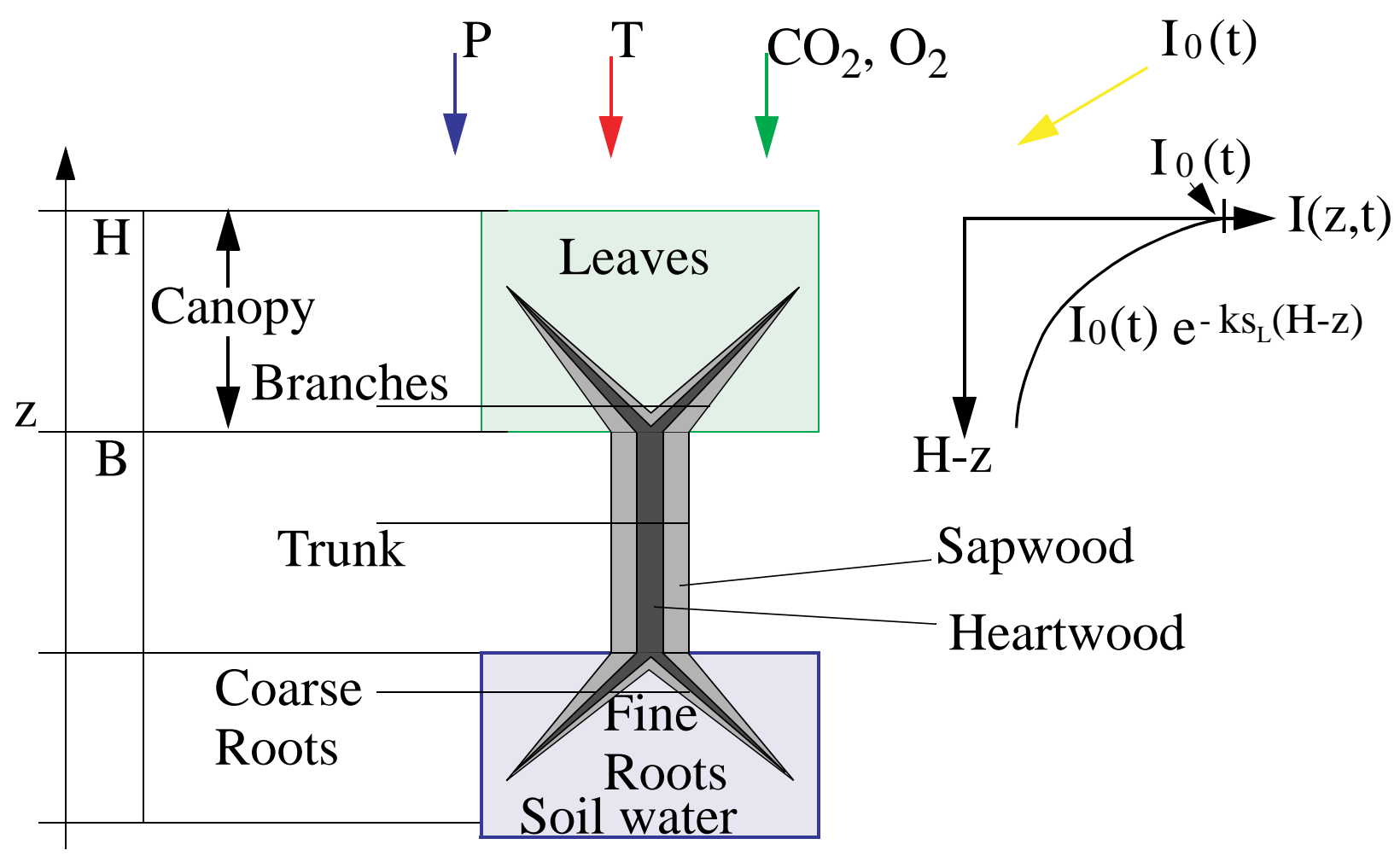

Figure 2: Idealized plant structure considered in the model. The symbols designate: the model variables mean stand height $\mathrm{H}$, bole height $\mathrm{B}$, and the independent variable height above ground $\mathrm{z}$; the daily forcing: precipitation $P$, temperature $T$,not reflected $P A R$ at time $\mathrm{t}$ of the day $I_{0}(t)$. The graph indicates light attenuation in the canopy with the light extinction coefficient $\mathrm{k}$, leaf density $s_{L}$, and PAR at height $\mathrm{z}$ in the canopy and time $\mathrm{t}$ of the day $I(z, t)$.

\subsubsection{Gross primary production}

Light dependent instantaneous gross photosynthesis of the leaf layer at height $\mathrm{z}$ in the canopy, $\mathrm{A}(\mathrm{z}, \mathrm{t})$, is calculated from the asymptotic function of absorbed PAR:

$$
A(z, t)=\frac{\Phi_{C} s_{L} P_{\max }(z) \phi I_{a b}(z, t)}{\phi I_{a b}(z, t)+\Phi_{C} s_{L} P_{\max }(z)}
$$

where $P_{\max }(z)$ is the maximal assimilation rate per square meter at height $\mathrm{z}$ in the canopy at 320 ppmv $\mathrm{CO}_{2}$ (ppmv=parts per million volume) and $\phi$ the quantum yield efficiency (Landsberg 1986).

Shade adapted leaves have lower maximal photosynthetic rates than sun adapted leaves (Lerch 1991). Therefore the maximal photosynthetic rate of the leaf layer at height $\mathrm{z}, P_{\max }(z)$, is assumed to equal the rate of the sun adapted leaves reduced by the fraction of light the layer receives:

$$
P_{\max }(z)=P_{\max }(H) \cdot \frac{I(z, t)}{I_{0}(t)}=P_{\max }(H) \cdot e^{-k s_{L}(H-z)} .
$$

For notational purposes we set $A_{\max }:=P_{\max }(H)$, which is the maximal assimilation rate of sun adapted leaves at 320 ppmv $\mathrm{CO}_{2}$ in $\left[\mu \mathrm{molCO}_{2} \mathrm{~m}^{-2} \mathrm{sec}^{-1}\right]$.

Substituting (8) and (12) into relation (11) gives:

$$
A(z, t)=k s_{L} \cdot e^{-k s_{L}(H-z)} \frac{\phi I_{0}(t) \Phi_{C} A_{\max }}{\phi k I_{0}(t)+\Phi_{C} A_{\max }},
$$


hence time and canopy integrations become independent.

Integration of $\mathrm{A}(\mathrm{z}, \mathrm{t})$ through the canopy and over the day results by using (9) in daily light dependent gross photosynthesis $G P P_{\text {std }}$ :

$$
G P P_{s t d}=\left(1-e^{-k L A I}\right) \int_{D a y} \frac{\Phi_{C} A_{\max } \phi I_{0}(t)}{\phi k I_{0}(t)+\Phi_{C} A_{\max }} d t
$$

\subsubsection{Plant respiration}

First the model estimates instantaneous herbaceous tissue and wood maintenance respiration separately at a reference temperature, $\mathrm{T}_{\text {ref }}$.

The herbaceous tissue respiration rate at height $\mathrm{z}$ and time $\mathrm{t}$ in the canopy at reference temperature, $\operatorname{Rh}(\mathrm{z})$, includes the respiration rate of the leaf layer at height $\mathrm{z}$ and the respiration rate of those roots supporting these leaves. Since shaded leaves contain less nitrogen and transpire less than sun leaves, we assume that the respiration rate declines from the top to the bottom of the canopy -as the assimilation rate.

At each height in the canopy the reference respiration rate for herbaceous tissue is assumed to be one tenth of the maximal assimilation rate at optimal temperature.

This assumption is reasonably in line with published measurements (Larcher 1984, Medina and Klinge 1983, Sprugel et al. 1995). Further, a combination of reported data relating the maximal assimilation rates and respiration rates with leaf nitrogen content (Evans 1989, Ryan 1991) results in:

$$
R h(H) \approx 0.05 A_{\max }
$$

As Ryan (1991) mentions the data used in relating leaf nitrogen content and leaf respiration rates tend to underestimate the respiration. Thus our assumption $R h(z) \approx 0.1 P_{\max }(z)$ seems reasonable -as it also includes the fine root respiration of the roots supporting the leaf layer at height $\mathrm{z}$.

The respiration of wood should not be estimated on the basis of total woody biomass or wood surface area because of a possibly large fraction of dead cells in woody plant parts (Ryan 1989). The center of a large stem or branch consists of heartwood which contains no living cells and provides only structural support. On the other hand, the cambium, the phloem as well as the sapwood, located between the cambium and heartwood, consist to certain fractions of living cells. The sapwood is generally able to conduct water and serves as storage of water and carbohydrates (Waring and Schlesinger 1985), thus it can be considered as the live support system for the leaves. In larger stems the main fraction of living cells is located in the sapwood (Ryan 1989). Therefore it seems appropriate to calculate sapwood respiration.

The sapwood volume index, SVI, is defined similar to LAI, and is estimated from

$$
S V I=\int_{-1}^{H} S A I(z) d z=\epsilon \int_{-1}^{H} L(z) d z=\epsilon\left(\int_{-1}^{B} L A I d z+\int_{B}^{H} \frac{L A I}{H-B} z d z\right) \approx \epsilon L A I \cdot H
$$

where $\epsilon$ is the ratio of accumulated leaf area above the height $\mathrm{z}$ to sapwood cross sectional area at height $\mathrm{z}$ in the canopy, $\mathrm{SAI}(\mathrm{z})$. Following the pipe model theory, $\epsilon$ can be assumed to be a constant (Shinozaki et al. 1964, Waring and Schlesinger 1985).

$\mathrm{H}$ is calculated from diameter at breast height, $d b h$, which in turn is determined from the model state variable woody biomass, $p w$ :

$$
\begin{aligned}
& d b h=0.001 \cdot p w^{0.521}, \\
& H=20 \cdot d b h^{0.4}
\end{aligned}
$$


The parameters of these allometric relations are derived from data collected by Whittaker and Marks (1975) and an approximation to an equation used by Prentice et al. (1993).

From above assumptions about the respiration rate of herbaceous tissue follows:

$$
R h(z)=R h(H) e^{-k s_{L}(H-z)} .
$$

For total respiration at height $\mathrm{z}$ at reference temperature we obtain:

$$
R t(z)=R h(H) e^{-k s_{L}(H-z)}+R s \cdot S A I(z),
$$

where $\mathrm{Rs}$ is the sapwood respiration rate at temperature $T=T_{\text {ref }}$ in $\left[\mu \mathrm{molCO}_{2} \mathrm{~m}^{-3} \mathrm{sec}^{-1}\right]$.

Integration of respiration through the canopy and over the day (neglecting the temperature diurnal cycle) yields with substituting (16) for the standard daily respiration rate, $R_{\text {std }}\left[\mu \mathrm{molm} \mathrm{m}^{-2} \mathrm{day} \mathrm{y}^{-1}\right]$ :

$$
R_{s t d}=86400\left[\frac{R h_{\max }}{k s_{L}}\left(1-e^{-k L A I}\right)+R s \epsilon H \cdot L A I\right] .
$$

$R h_{\max }:=0.1 A_{\max }$ is the maximal respiration rate of herbaceous biomass (sun leaves and their roots) at $T=T_{\text {ref }}$ in $\left[\mu \mathrm{molCO}_{2} \mathrm{~m}^{-2} \mathrm{sec}^{-1}\right]$; Rs is assumed to be $100 \cdot R l_{\text {max }}$.

\subsubsection{Environmental factors $\Phi_{T}, \Phi_{D}, \Phi_{C}$ and $\mu_{T}$}

We shall refer to the environmental factors $\Phi_{T}, \Phi_{D}, \Phi_{C}$ and $\mu_{T}$ also as indices as they really are indicators of the vigour of assimilation and respiration in the corresponding temperature, moisture and $\mathrm{CO}_{2}$ regimes.

The temperature index $\Phi_{T}$ is defined by:

$$
\Phi_{T}(T)=\left\{\begin{array}{cc}
1.5 \frac{\left(T-T_{\min }\right)^{1.5}\left(T_{\max }-T\right)}{\left(0.6\left(T_{\max }-T_{\min }\right)\right)^{2.5}} & T_{\min } \leq T \leq T_{\max } \\
0 & \text { else }
\end{array}\right.
$$

using mean daily temperature, T. $\Phi_{T}$ is a root function being zero at $T_{\min }$ and $T_{\max }$ and one at $T_{o p t}=\frac{2}{5}\left(T_{\min }+1.5 T_{\max }\right)$. This is an empirical fit to the temperature dependence of the activity of the enzymes which first accept $\mathrm{CO}_{2}$ in the metabolism (Johnson et al. 1954, Lommen et al. 1971). Using such an empirical function has the advantage that only two reasonably well known parameters, $T_{\min }$ and $T_{\max }$ (see eg. Larcher 1984), have to be specified. The essential drawback is that the optimal temperature range calculated by equation (22) is quite small.

The drought index $\Phi_{D}$ is modelled by the ratio of actual to potential evapotranspiration

$$
\Phi_{D}=\frac{A E T}{P E T} \text {. }
$$

Actual and potential evapotranspiration are calculated by the soil water model (see 2.2).

$\Phi_{C}$, the functional dependence of $\mathrm{A}(\mathrm{z}, \mathrm{t})$ on the atmospheric $\mathrm{CO}_{2}$-concentration, is simulated as in Prentice et al. (1993):

$$
\Phi_{C}=1+\frac{0.7\left(C O_{2}-320\right)}{0.7 \cdot 320-,}
$$

where $\mathrm{CO}_{2}$ is the mean annual atmospheric $\mathrm{CO}_{2}$-concentration of the current year and, the $\mathrm{CO}_{2}$ compensation point of photosynthesis, both expressed in ppmv.

Standard daily respiration is modified by the Arrhenius relationship, $\mu_{T}(T)$ :

$$
\mu_{T}(T)=e^{-\rho\left(\frac{1}{T^{K}}-\frac{1}{T_{r e f}^{K}}\right)}
$$

$T^{K}$ is the mean daily temperature and $T_{r e f}^{K}$ the reference temperature $T_{\text {ref }}$ in Kelvin. $\rho$ is chosen such that a $Q_{10}$ of 2 results at $20^{\circ} \mathrm{C}$ (Amthor 1984, Sprugel et al. 1995). 


\subsection{Phenology}

Budburst and leaf abcission are initiated in response to environmental variables. Note that leaf fall implies the shedding of fine roots due to the structure of the model, assuming a fixed root/shoot ratio.

For both, budburst and leaf fall the biomes were divided into two categories (Table 1).

\subsubsection{Leaf growth initiation}

\begin{tabular}{|r|l|c|c|c|} 
No. & Biome & Type & Growth trigger & Leaf fall trigger \\
\hline 1 & Tropical Dry Forest/Savannah & deciduous & NPP & AET/PET \\
2 & Tropical Seasonal Forest & mixed & NPP & AET/PET \\
3 & Tropical Rain Forest & evergreen & NPP & AET/PET \\
4 & Xerophytic Woods/Shrub & evergreen & NPP & AET/PET \\
5 & Hot Desert & evergreen & NPP & AET/PET \\
6 & Warm Grass/Shrub & mixed & NPP & AET/PET \\
7 & Broad-leaf Evergr./Mixed Forest & evergreen & GDD & Temperature \\
8 & Temperate Deciduous Forest & deciduous & GDD & Temperature \\
9 & Cool Mixed Forest & mixed & GDD & Temperature \\
10 & Cold Mixed Forest & mixed & GDD & Temperature \\
11 & Cool Coniferous Forest & evergreen & GDD & Temperature \\
12 & Cool Grass/Shrub & mixed & NPP & Temperature \\
13 & Cold Deciduous Forest & deciduous & GDD & Temperature \\
14 & Boreal Forest & evergreen & GDD & Temperature \\
15 & Tundra & mixed & NPP & Temperature \\
16 & Semidesert & evergreen & GDD & Temperature
\end{tabular}

Table 1: Biomes considered in the model, their type and trigger used to initiate budburst and leaf abcission.

Budburst in the tundra, the tropical biomes, and the grasslands is assumed to be NPP regulated. The vegetation grows whenever the growth conditions are favourable indicated by calculated values of $\frac{\mathrm{dNPP}}{\mathrm{dLAI}}$ larger than zero. All other biomes are temperature regulated in the model. They require a certain amount of growing degree days on the basis of $5^{\circ} C, G D D_{5}$. This amount depends on the on the number of days with mean daily temperature below $5^{\circ} C$, $N C D_{5}$, (Murray et al. 1989). Budburst is triggered as soon as the following condition is met:

$$
G D D_{5} \geq a+b e^{-c N C D_{5}} .
$$

The rationale for this relation is that the more cold days have passed in the time course of winter and spring, the smaller the chance that new leaves might be damaged by a sudden frost, thus the lower the $G D D_{5}$ requirement may become.

The parameters $a, b$, and $c$ were derived from an evaluation of NDVI data separately for each biome. We used the mean for each biweekly interval of the NDVI data for 1986-1991 from Gallo (1992).

For this derivation the vegetation distribution of the BIOME I model could not be used because it does not include agricultural areas and hence does not show the existing biome distribution. Therefore a comparison with satellite data, which refer to the actual vegetation would introduce a misfit. Instead, we used the vegetation distribution as given by Olson et al. (1983) as their data are explicitly based on an assessment of actual existing vegetation. Olson 
et al. (1983) employ vegetation types different from the BIOME I biomes. Most of these types can be assigned to one of the BIOME I biomes according to Prentice et al. (1992) (Table 2).

\begin{tabular}{|c|c|c|}
\hline No. & Olson's 1983 Ecosystem complex & Biome I types \\
\hline 1 & tropical savannah (27), tropical dry forest (13) & Tropical Dry Forest/Savannah \\
\hline 2 & trop. seasonal forest (9) & Tropical Seasonal Forest \\
\hline 3 & equator. evergreen forest (10) & Tropical Rain Forest \\
\hline 4 & $\begin{array}{l}\text { highland shrub }(20) \text {, med. grazing }(21) \text {, semiarid } \\
\text { woods }(22) \text {, succulent thorns }(25) \text {, low shrub }(37)\end{array}$ & Xerophytic Woods/Shrub \\
\hline 5 & $\begin{array}{l}\text { warm irrigated dryland (15), hot desert (39), } \\
\text { sand desert (43) }\end{array}$ & Hot Desert \\
\hline 6 & warm grass/shrub (19) & Warm Grass/Shrub \\
\hline 7 & $\begin{array}{l}\text { warm mixed forest }(6) \text {, warm conifer forest }(7) \text {, } \\
\text { tropical montane complexes }(8)\end{array}$ & Broad-leaf Evergr./Mixed forest \\
\hline 8 & warm deciduous forest $(5)$ & Temperate Deciduous Forest \\
\hline 9 & cool mixed forest $(4)$ & Cool Mixed Forest \\
\hline 11 & cool conifer forest $(3)$ & Cool Coniferous Forest \\
\hline 12 & $\begin{array}{l}\text { cool irrigated dryland (16), cool grass/shrub (18), } \\
\text { siberian parks }(23)\end{array}$ & Cool Grass/Shrub \\
\hline 14 & $\begin{array}{l}\text { main taiga }(2) \text {, north. taiga }(26) \text {, south. } \\
\text { taiga }(32) \text {, equatorial. south. taiga }(33)\end{array}$ & Boreal Forest \\
\hline 15 & $\begin{array}{l}\text { cold irrigated dryland }(17), \text { wooded } \\
\text { tundra }(41), \text { tundra }(42)\end{array}$ & Tundra \\
\hline 16 & cool desert $(40)$ & Semidesert \\
\hline 17 & polar desert (44), ice (45) & Ice \\
\hline
\end{tabular}

Table 2: Ecosystem complexes distinguished by Olson et al. (1983) and their assignment to the BIOME I biomes according to Prentice et al. (1992). Coastal edges, wetlands (heaths, moors (24); marsh, swamp (35); mangroves (36); bogs, bog woods (38)) and agricultural areas (cool crops (11); warm crops (12); paddylands (14); cool field/woods (28); warm field/woods (29); warm for./field (30); cool for./field (31)) have been excluded.

From this assignment we obtained a classification of most existing natural vegetation according to Olson et al. (1983) into the BIOME I biomes. Thus only such pixels entered the evaluation of the NDVI data which are actually occupied by the biome considered -assuming that the Olson et al. (1983) data match the real vegetation distribution during the time period of the NDVI data.

For each pixel within the biome areas according to the aggregated Olson's 1983 ecosystem types we determined the date of the largest increase in the NDVI data after the monthly mean temperature had reached $5^{\circ} \mathrm{C}$ (as indication of budburst). From the climate data we determined $G D D_{5}$ and $N C D_{5}$ until those dates. We obtained for each biome a set of $G D D_{5}$ and $N C D_{5}$ data pairs, representing the climate conditions up to the time of budburst. For each biome equation (26) was fitted to these data pairs.

It remains somewhat questionable whether the data of Olson et al. (1983) really represent the vegetation distribution seen by the satellites. Clearly this is very uncertain considering the fact that more than 10 years exist between collection of the data used by Olson et al. (1983) and the NDVI data. However one might hope that the mismatch is relatively small in the temperate biomes. Furthermore, because of continuity arguments, the error introduced by 
small misfits in the vegetation distribution in the coefficients $a, b$, and $c$ is expected to be small as well.

Unfortunately Olson et al. (1983) do not distinguish the biomes Cold Mixed Forest and Cold Deciduous Forest, therefore no parameters could be derived for these biomes. Instead, we used the parameters obtained for Boreal Forest. This is presumably not appropriate -at least not for the cold deciduous forest- as we show later.

In the case of deciduous types leaf fall in the tropical biomes is assumed to be soil moisture regulated and in the temperate biomes triggered by temperature. The tropical biomes initiate

leaf fall whenever $\frac{A E T}{P E T} \leq 0.4$. The temperate biomes initiate leaf fall when the mean monthly temperature drops below $5^{\circ} \mathrm{C}$.

\subsubsection{Allocation}

Allocation depends on the environmental conditions prevailing during the current time step. Formally it is defined by two coefficients, $h_{2}$ and $h_{3}$, calculated every timestep which determine the fractions of the assimilate pool which are transferred to herbaceous and woody living biomass respectively.

The extent of the leaf area is of crucial importance for plants. A large LAI is advantageous as it allows more photosynthesis (gross production). On the other hand, it requires higher investments of material and energy in maintenance and construction which eventually reduce the net carbon gain.

Accordingly, the value of the currently optimal and structurally maximal possible LAI is central in the model allocation scheme. This LAI value, $L A I_{\max }$, is defined as the minimum of two indicators of the current climate and model state: First, the optimal LAI, giving rise to maximal NPP under the prevailing growing conditions, $L A I_{n p p}$. Secondly, the maximal LAI which could be held physically by the vegetation, $L A I_{v e g}$, i.e. the LAI value which is structurally maximal possible with the current amount of biomass. Thus: $L A I_{\max }=\min \left(L A I_{n p p}, L A I_{\text {veg }}\right)$, where $L A I_{n p p}$ is determined from $\frac{d N P P}{d L A I}\left(L A I_{n p p}\right)=0$ assuming the prevailing growth conditions. $L A I_{v e g}$ is derived from the reduced specific leaf area, $S L A^{*}$, and a fixed fraction of total plant biomass, fh, relating total plant biomass, $p_{t o t}$, to herbaceous plant biomass:

$$
L A I_{v e g}=S L A^{*} \cdot f h \cdot p t o t
$$

As soon as budburst is triggered, $h_{2}$ and $h_{3}$ are defined by the following equations:

$$
\begin{aligned}
& h_{2}=\frac{L A I_{\max }-L A I}{L A I_{\max }} \cdot \min \left(0.25, \frac{p a}{3 p l_{\max }}\right) \\
& h_{3}=\min \left(\frac{p a}{3 p l_{\max }}\left(1-\frac{L A I_{\max }-L A I}{L A I_{\max }}\right), \frac{p w_{\max }}{p a}\right),
\end{aligned}
$$

where $p a$ is the size of the assimilate pool, $p l_{\max }$ the amount of herbaceous phytomass corresponding to $L A I_{\max }$, and $p w_{\max }$ the maximal amount of woody biomass defined as a fixed fraction of total plant biomass, $p w_{\max }=f w \cdot p t o t$. The term $\frac{p a}{3 p l_{\max }}$ ensures that growth is slowed down as soon as the amount of carbon in the assimilate pool drops below three times of the currently optimal amount of herbaceous biomass. If necessary, the values of $h_{2}$ and $h_{3}$ are adjusted such that $0 \leq h_{2}, h_{3} \leq 1$. The fractions relating total plant biomass to woody and herbaceous plant biomass, fh and fw, are the same as used in the HRBM (Mack 1993, Esser et al. 1994). 


\subsubsection{Litter production}

Litter production is proportional to the corresponding pool sizes. In evergreen biomes herbaceous litter production occurs with a fixed rate throughout the year. The production rate for woody litter is in each biome constant throughout the year. Both these rates are derived from the turnover times of herbaceous and woody tissue as defined in the HRBM. For the sake of simplicity, leaf area of mixed biomes is assumed to be $50 \%$ deciduous and $50 \%$ evergreen. For deciduous types we assume that leaf fall occurs during one full month. Thus in mixed biomes the leaf litter production rates are adjusted such that one month after the start of the leaf fall $\left(\frac{1}{2}+\frac{1}{12 \cdot 2}\right)$ of the initial herbaceous biomass is shed -assuming that the turnover time of the evergreen herbaceous material is two years. $11 \%$ of the herbaceous and $30 \%$ of the produced woody litter are transferred to the SOC pool (Esser 1991), the remainder to the corresponding litter pools.

\subsection{Decomposition}

The daily decomposition rates of herbaceous and woody litter as well as SOC are defined by the relations obtained by Esser et al. (1982), Esser (1991) from measurements adjusted by the time step length:

$$
\begin{aligned}
l d r_{x}= & \frac{\log 2}{360 \cdot 50} \cdot \min \left(l d T_{x}, l d p_{x}\right) ; x=h, w \\
l d T_{h}= & 7.67 \cdot \exp \left(0.0926\left(T_{t}+6.41\right)\right)+17.06 \\
l d p_{h}= & \left(\frac{50}{\left.0.0215+\exp \left(4.2-0.0053 p_{t}\right)\right)}+670\right) \cdot\left(\frac{0.094}{0.7+\exp \left(0.0023 p_{t}-5.05\right)}+0.076\right) \\
& \cdot 0.64 \cdot\left(1-\exp \left(-0.001 p_{t}\right)\right) \\
l d T_{w}= & 2.67 \cdot \exp \left(0.0522\left(T_{t}+31.63\right)\right)-2.51 \\
l d p_{w} & =\left(\frac{27.8}{\left.0.021+\exp \left(8.53-0.0095 p_{t}\right)\right)}+712\right) \cdot\left(\frac{0.126}{1.51+\exp \left(0.003 p_{t}-4.65\right)}+0.05\right) \\
l d r_{s}= & 0.5 \cdot\left(1-\exp \left(-0.001 p_{t}\right)\right)
\end{aligned}
$$

where $T_{t}$ is the mean temperature of the timestep and $p_{t}$ is the precipitation of the timestep multiplied by $360 /$ (timestep length in days) and h,w, and $\mathrm{s}$ refer to herbaceous and woody litter and SOC.

\section{Results and discussion}

The model was run with daily NPP calculation and an integration time step of six days. The daily climate data were generated by a linear interpolation of climatological mean monthly data from the IIASA database of Leemans and Cramer (1991). The atmospheric $\mathrm{CO}_{2}$-concentration was kept constant at $338 \mathrm{ppmv}$. After 300 years simulation the model calculated a global annual NPP of about $47 \mathrm{GtCyr}^{-1}$. The global annual net carbon balance was about $0.2 \mathrm{GtCyr}^{-1}$ indicating a state close to equilibrium. 


\subsection{Local seasonal cycles}

Figures 3 to 6 depict seasonal cycles of temperature, precipitation, plant absorbed short wave radiation, soil moisture in the top graphs, the growth and respiration factors in the center graphs, and the resulting carbon fluxes NPP, total litter production, total litter decay, and net carbon flux to the atmosphere in the bottom graphs in four selected regions occupied by different biomes. Since woody litter production rates were specified constant in time the variations in total litter production show mainly the variations in herbaceous litter production. The same holds essentially also for the litter decay. Note the varying scales on the figures.

Tropical rain forest (Central Amazonas); $1^{\circ}$ to $3^{\circ} \mathrm{S}, 66^{\circ}$ to $68^{\circ} \mathrm{W}$

This tropical rainforest region (Fig. 3) is characterized by good growing conditions throughout the year (Fig. 3 top).

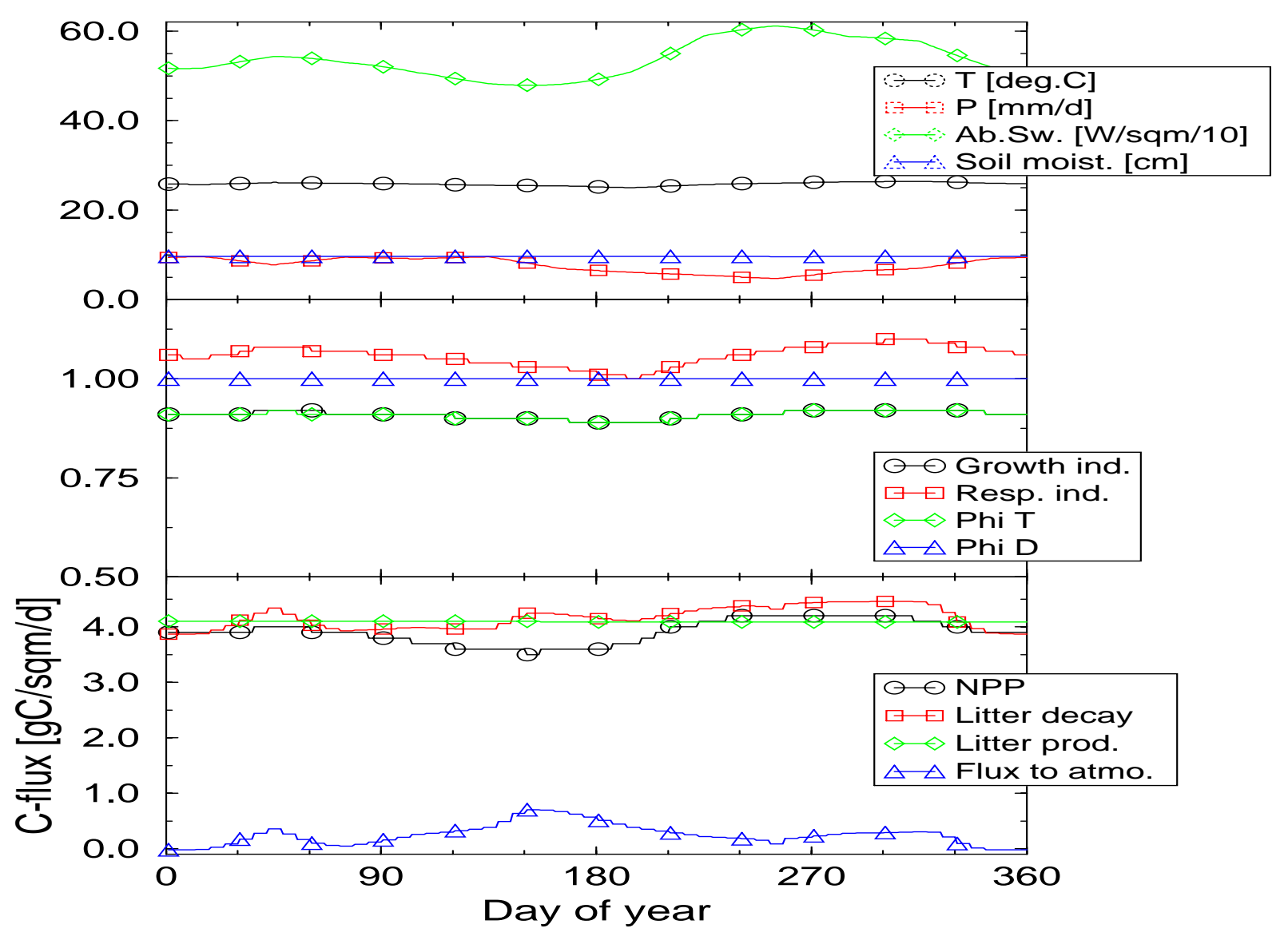

Figure 3: Input data and model simulated variables in a region of tropical rain forest in Central Amazonas, $1^{\circ}$ to $3^{\circ}$ South, $66^{\circ}$ to $68^{\circ}$ West. Top: daily temperature, precipitation, plant absorbed short wave radiation, and soil moisture; center: daily growth $\left(\Phi_{T} \Phi_{D}\right)$ and respiration, and temperature and drought index for assimilation; bottom: daily NPP, total litter production, total litter decay, and net carbon flux to the atmosphere.

The drought index is always optimal and the temperature dependent indices, $\Phi_{T}$ and $\mu_{T}$ (Fig. 3 center) are almost constant during the year.

Thus NPP shows only small variations as the net carbon flux (Fig. 3 bottom). The net carbon flux is slightly positive. This results from the litter production and litter decay being slightly larger than the NPP. This imbalance is an artefact of the initialization and not of 
importance on larger scales..

Tropical seasonal forest (Northern Mato Grosso); $6^{\circ}$ to $8^{\circ} \mathrm{S}, 56^{\circ}$ to $58^{\circ} \mathrm{W}$

In this region temperature is close to $25^{\circ} \mathrm{C}$ throughout the year (Fig. 4).

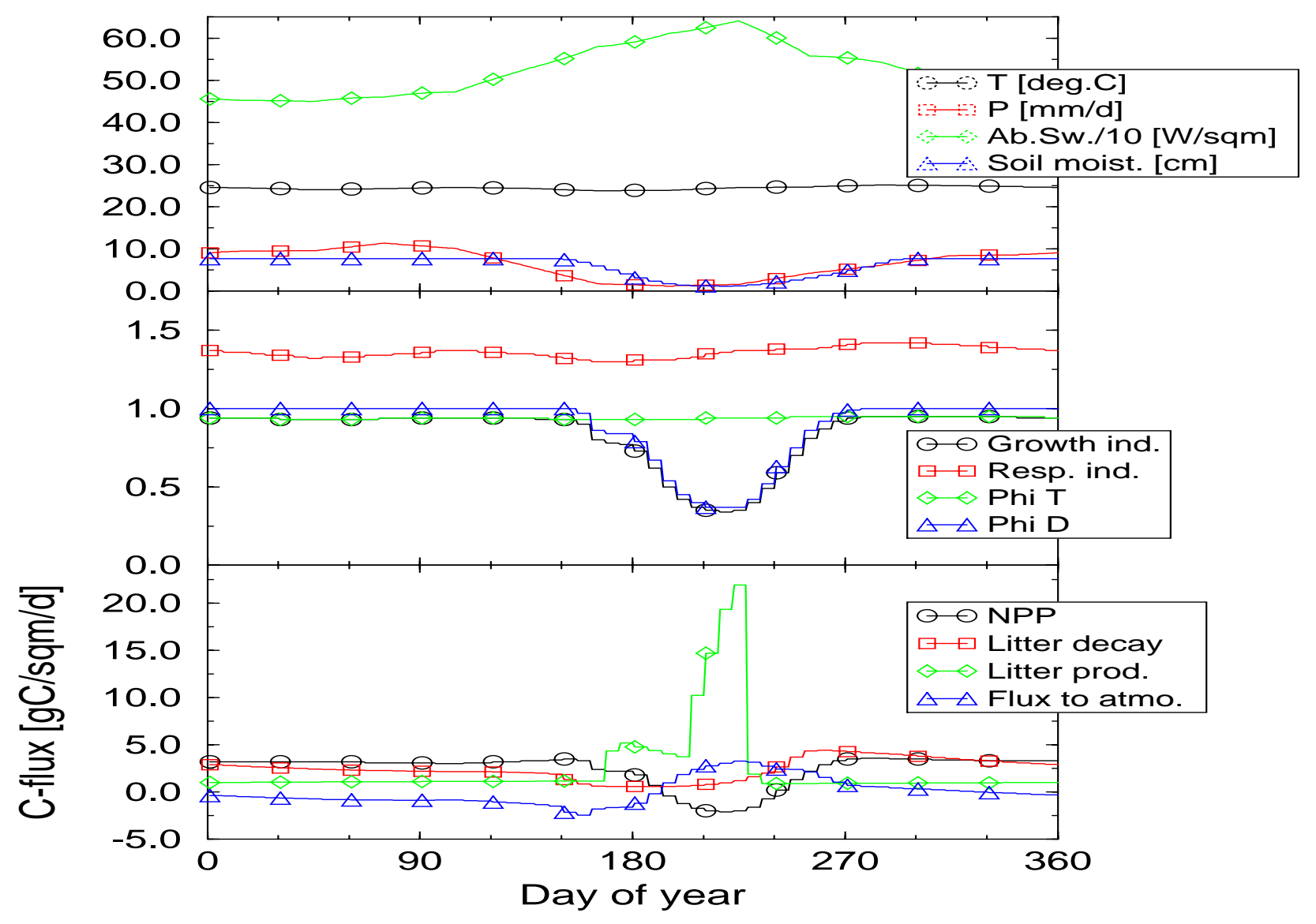

Figure 4: Input data and model simulated variables in a region of tropical seasonal forest in Northern Mato Grosso, $6^{\circ}$ to $8^{\circ}$ South, $56^{\circ}$ to $58^{\circ}$ West. Top: daily temperature, precipitation, plant absorbed short wave radiation, and soil moisture; center: daily growth $\left(\Phi_{T} \Phi_{D}\right)$ and respiration, and temperature and drought indices for assimilation; bottom: daily NPP, total litter production, total litter decay, and net carbon flux to the atmosphere.

Precipitation shows a strong seasonality with decreased values from mid May to mid September. These low precipitation values lead to a strong reduction of soil moisture and severe drought stress from July to mid September. Despite increased sunshine the dry season results in markedly decreased NPP values from June to September. NPP becomes even negative due to continuously high respiration costs and reduced GPP from mid July to end of August. The figure shows also clearly the increase in litter production due to shedding of herbaceous biomass as consequence of the onset of the dry season. Litter decay is elevated during August to November as result of the increased litter production during the dry season. These interactions add up to a positive carbon flux to the atmosphere from July to November resulting first from decreased NPP and then from increased heterotrophic respiration. Similar soil moisture and NPP patterns have been found during the FIFE field study (Desjardins et al. 1992, Verma et al. 1992).

Temperate deciduous forest (Appalachian Mountains); $37^{\circ}$ to $39^{\circ} \mathrm{N}, 76^{\circ}$ to $78^{\circ} \mathrm{W}$ 
At this location the seasonal characteristics of soil moisture show a seasonal pattern with minimal values in summer and maximal values in winter, opposing the seasonal cycle in temperature (Fig. 5).

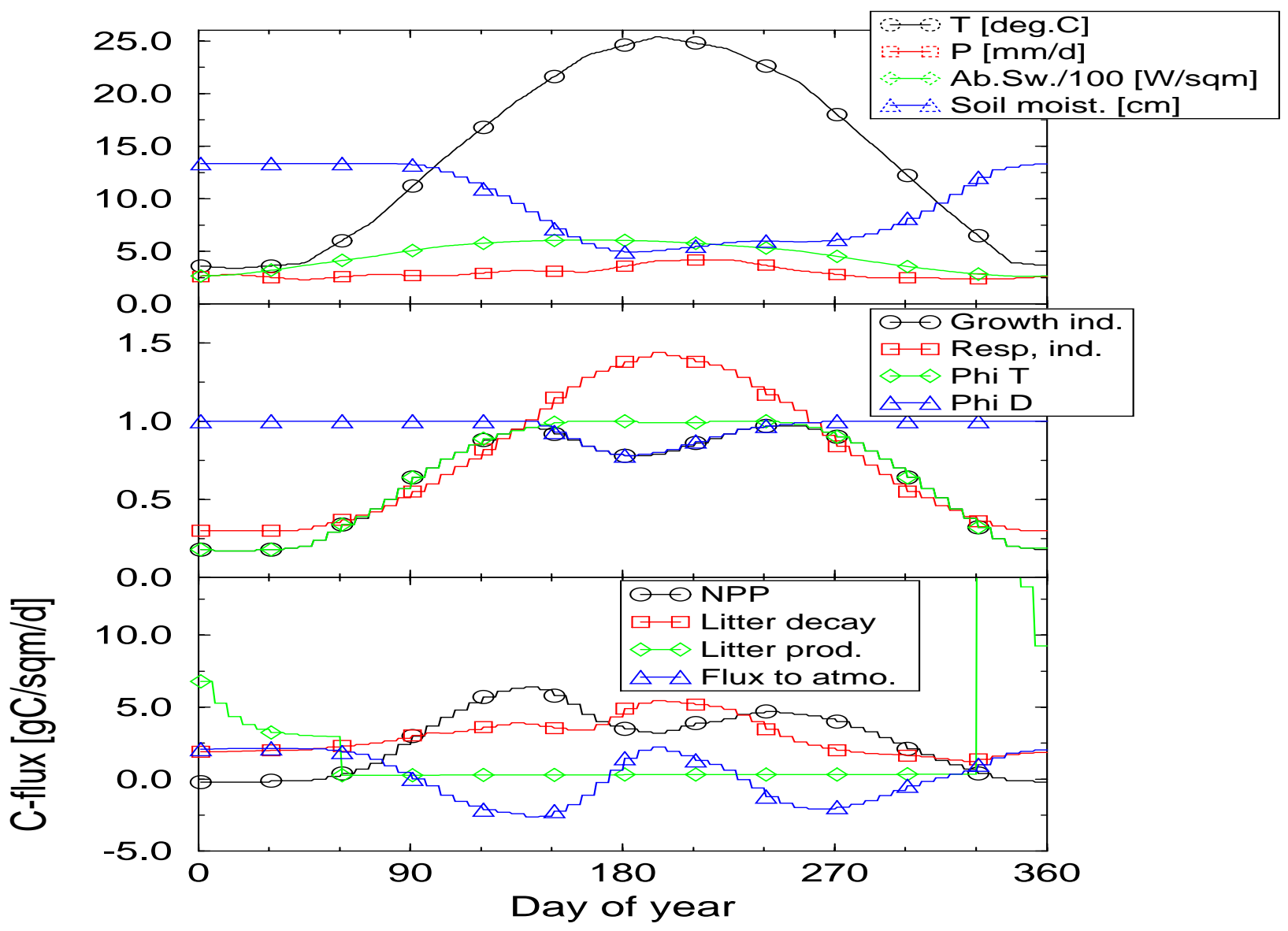

Figure 5: Input data and model simulated variables in a region of temperate deciduous forest in the Appalachian Mountains, $37^{\circ}$ to $39^{\circ}$ North, $76^{\circ}$ to $78^{\circ}$ West. Top: daily temperature, precipitation, plant absorbed short wave radiation, and soil moisture; center: daily growth $\left(\Phi_{T} \Phi_{D}\right)$ and respiration, and temperature and drought indices for assimilation; bottom: NPP, total litter production, total litter decay, and net carbon flux to the atmosphere.

The seasonal development of the drought index $\Phi_{D}$ mirrors the development of soil moisture. The temperature index $\Phi_{T}$ for assimilation reaches its maximum at the end of June. Slightly decreased values during July indicate temperatures above the optimum, $T_{\text {opt }}$. The respiration index becomes maximal in July.

NPP increases during spring, then shows a slight summer depression and increases again in late August/September. This pattern reflects the simultaneous increase of assimilation and plant respiration in spring, the depressed summer assimilation due to temperature and drought stress in June and July with further increased plant respiration, followed by decreased plant respiration but prevailing good growth conditions in August and September. Herbaceous litter production starts at the beginning of December with temperatures below $5^{\circ} \mathrm{C}$. Total litter production reaches $50 \mathrm{~g} \mathrm{Cm}^{-2} \mathrm{~d}^{-1}$ (maximal values are not shown for readability of the figure). The litter and SOC decay is around $2.5 \mathrm{gCm}^{-2} \mathrm{~d}^{-1}$ throughout the year and rises up to 5 $\mathrm{gCm}^{-2} \mathrm{~d}^{-1}$ during June and July. The net carbon flux to the atmosphere is positive during 
winter, negative for March to mid May, then positive again due to drought stress and excessive plant respiration, and finally negative again in late summer and early autumn.

Warm grassland (Great Plains, Kansas); $39^{\circ}$ to $40^{\circ} \mathrm{N}, 99^{\circ}$ to $101^{\circ} \mathrm{W}$

This warm grassland region (Fig. 6) is characterized by low winter (below $0^{\circ} \mathrm{C}$ ), warm summer (above $25^{\circ} \mathrm{C}$ ) temperatures, and low precipitation throughout the year with a small maximum in late spring to early summer.

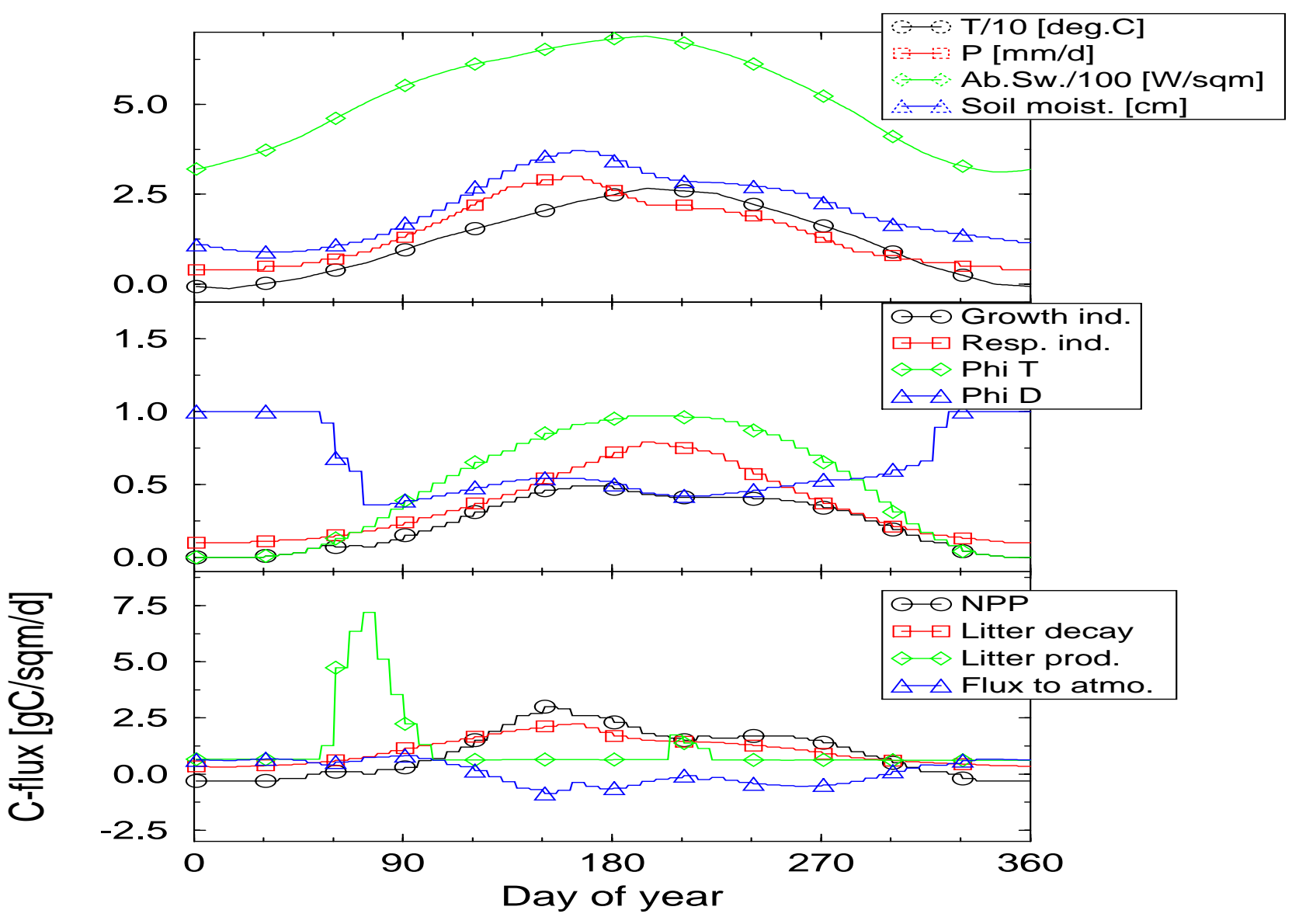

Figure 6: Input data and model simulated variables in a region of warm grassland in the Great Plains, Kansas, $39^{\circ}$ to $40^{\circ}$ North, $99^{\circ}$ to $101^{\circ}$ West. Top: daily temperature, precipitation, plant absorbed short wave radiation and soil moisture; center: daily growth $\left(\Phi_{T} \Phi_{D}\right)$ and respiration, and temperature and drought indices for assimilation; bottom: NPP, total litter production, total litter decay, and net carbon flux to the atmosphere.

These climatic conditions lead to drought stress throughout the whole year, except in the winter - the drought index being below 0.5 for most of the year and one in winter. However no high temperature stress on assimilation occurs despite the drought stress.

Consequently the model predicts a positive NPP throughout the whole growing season (1-2 $\left.\mathrm{gCm}^{-2} \mathrm{~d}^{-1}\right)$. Leaf fall occurs at the end of winter due to the temperature-moisture relations which imply that $\Phi_{D}$ drops below the leaf fall threshold of 0.4 only at this time of the year. During summer heterotrophic respiration is limited by precipitation and during winter by temperature. Throughout the summer it is larger than about $1 \mathrm{gCm}^{-2} \mathrm{~d}^{-1}$. In winter and spring heterotrophic respiration remains significantly above zero, resulting in a positive carbon flux to the atmosphere during this part of the year. 


\subsection{Annual NPP}

In order to evaluate the simulated annual NPP rates of the new model we compare our results with (a) local ground NPP observations, (b) biome averaged NPP of the HRBM and the data of Olson el al. (1983), and (c) the global NPP distribution predicted by the HRBM. Whenever necessary plant dry matter units were converted to carbon units by applying a factor of 0.45 (Whittaker and Likens 1973).

(a) Figure 7 shows a scatter plot comparing the locally measured NPP data with the simulated annual NPP rates of the corresponding grid cells. Biome and the number of point measurements per biome are also indicated.

Such a comparison suffers intrinsically from a several problems: Firstly, the model simulation represents a mean over the entire grid cell, whereas the local measurements reflect the reaction of vegetation to local conditions, which can be very different from the grid cell mean. A consequence is that the observations will exhibit more variability than the model results. Secondly, the point measurements are subject to unknown and quite often significant errors.

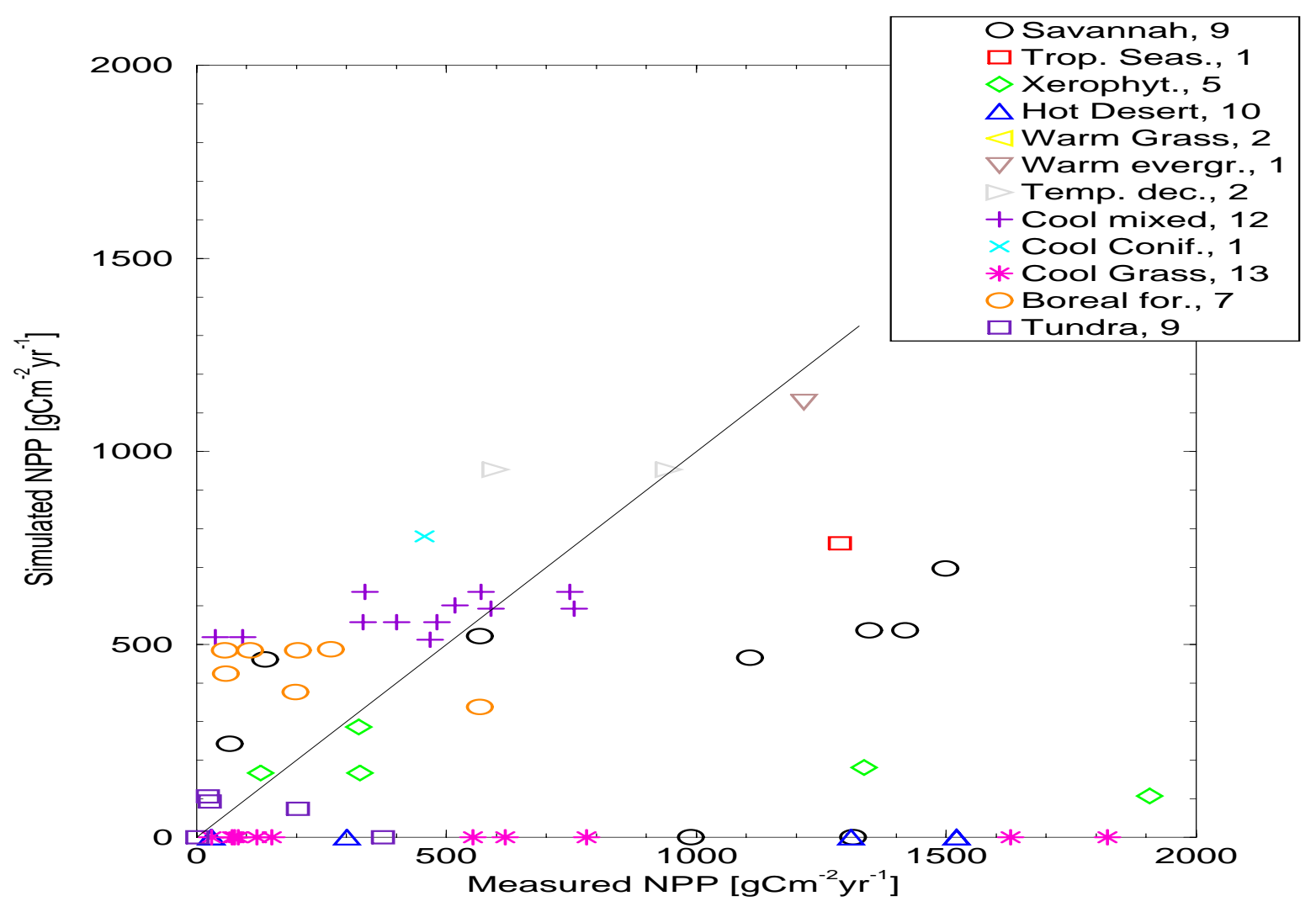

Figure 7: Simulated annual NPP of the new model plotted against point measurements of annual NPP in different biomes. Units are $\left[\mathrm{gCm}^{-2} \mathrm{yr}^{-1}\right]$.

The observed local ground NPP rates were selected from the data of Lieth (1975) and a database of Esser (1984). Again, since we assume a potential biome distribution which is different from the real existing, a screening had to be applied to the measured data: Firstly we extracted from the point measurements only those points where the Olson and BIOME I classification coincide. We obtained a set of 70 point NPP measurements. 
Then we removed all data points where the original description of the observed data indicated a vegetation different than the Olson class. We finally retained the 48 point data shown in Fig. 7.

Considering the above caveats, the figure indicates that the NPP rates of forests (tropical seasonal, warm evergreen, temperate deciduous, cool mixed, cool coniferous, boreal) are in general reasonably well simulated with a tendency towards overestimation $\left(\mathrm{r}^{2}=0.52\right)$. The annual NPP of the Savannah points exhibits a large scatter and the model shows a general underestimation in this biome. The simulation of annual NPP rates of the points in the biomes warm and cool grass/shrub and Tundra is not satisfying for reasons discussed below.

(b) For a preliminary model intercomparison with the HRBM we used the results of a simulation experiment with the standard HRBM (Esser 1991) where we forced the model with fixed climate using the IIASA climatologies, and the observed mean annual atmospheric $\mathrm{CO}_{2}$-concentration of 1980 . From the results of the HRBM we calculated annual NPP of potential vegetation which should be comparable with the NPP estimates of our new model. In this simulation the HRBM calculated a global potential NPP of about 51 GtC per year. Figure 8 shows a comparison of mean annual NPP rates simulated with the new model, with the standard HRBM, and based on observational data compiled by Olson et al. (1983).

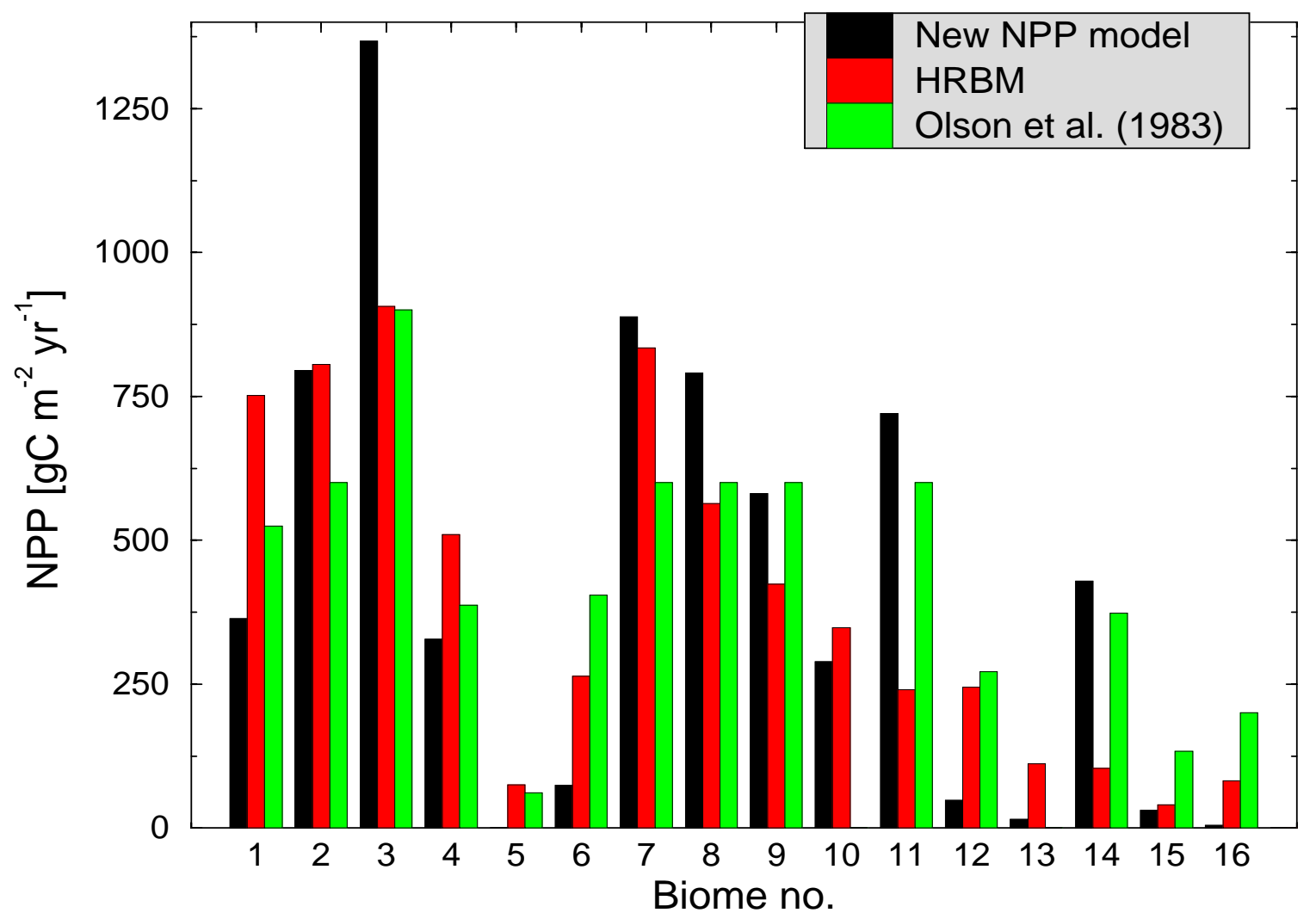

Figure 8: Mean annual NPP for each biome in $\left[\mathrm{gCm}^{-2} \mathrm{yr}^{-1}\right]$ from the simulation of new model (black), the HRBM (dark grey) and the data of Olson et al. (1983) (light grey)

Several caveats have to be kept in mind in such a comparison. As mentioned before, the data of Olson et al. (1983) refer to the actual natural vegetation existing before 
approximately 1980 whereas both models use the BIOME I map of potential vegetation. Furthermore the vegetation classification used by Olson et al. (1983) is different from the one used in the BIOME I model. Therefore we applied again the aggregation of the Olson et al. (1983) vegetation types to the BIOME I types as described in section 2.4.1. Finally, the compilation of Olson et al. (1983) does not contain any data for the potential natural NPP on areas subjected to anthropogenic influence (nearly all of central and eastern Europe, eastern United States, northern China, northern India, southern Australia and several other smaller regions).

On the basis of these uncertainties Fig. 8 indicates that the new NPP model gives quite good results for most forest formations with the exception of cold deciduous forest. For this biome no parameters for leaf budburst could be derived from the satellite data and therefore the same values as for boreal forest were used. This might be a reason for the failure of the model in this biome. The NPP estimation for tropical rain forest results in too high values. Possibly this overestimation results from ignoring the temperature dependence of quantum yield efficiency and the fact that the model does not include growth respiration.

Furthermore the results for the grass/shrub formations, hot desert, tundra, and cool semidesert are not satisfying. This might be related in part to the fact that the model formulation does not permit a separate treating of belowground biomass. Thus, if large parts of the leaves are shed the proportionate amount of fine roots is also shed as litter. Hence leaf growing in the next growing season does also require the regrowth of fine roots as leaves and fine roots are related by a fixed root/shoot ratio. This might not be realistic in biomes dominated by herbaceous plants. In the case of the hot environments the deficiencies possibly result from the fact, that the model was forced with daily precipitation data obtained from a smooth distribution of monthly precipitation throughout the month. This might lead to high drought stress during the entire growing period as the soil water pool is never filled as compared to a case with few but stronger precipitation events and we neglect any plant internal water stores.

(c) Fig. 9 and Fig. 10 display the global distributions of annual potential NPP simulated by the HRBM and the new model.

The weaknesses of the new model in the grass and desert biomes account for most areas in Fig. 10 with an annual NPP of less than $25 \mathrm{gCm}^{-2} \mathrm{yr}^{-1}$. In the other biomes the new model simulates generally a higher annual NPP than the HRBM. Furthermore the broad features indicate that the new NPP formulation is more dominated by the biome dependent parameters as compared to the HRBM formulation which is predominantly climate and soil controlled. 


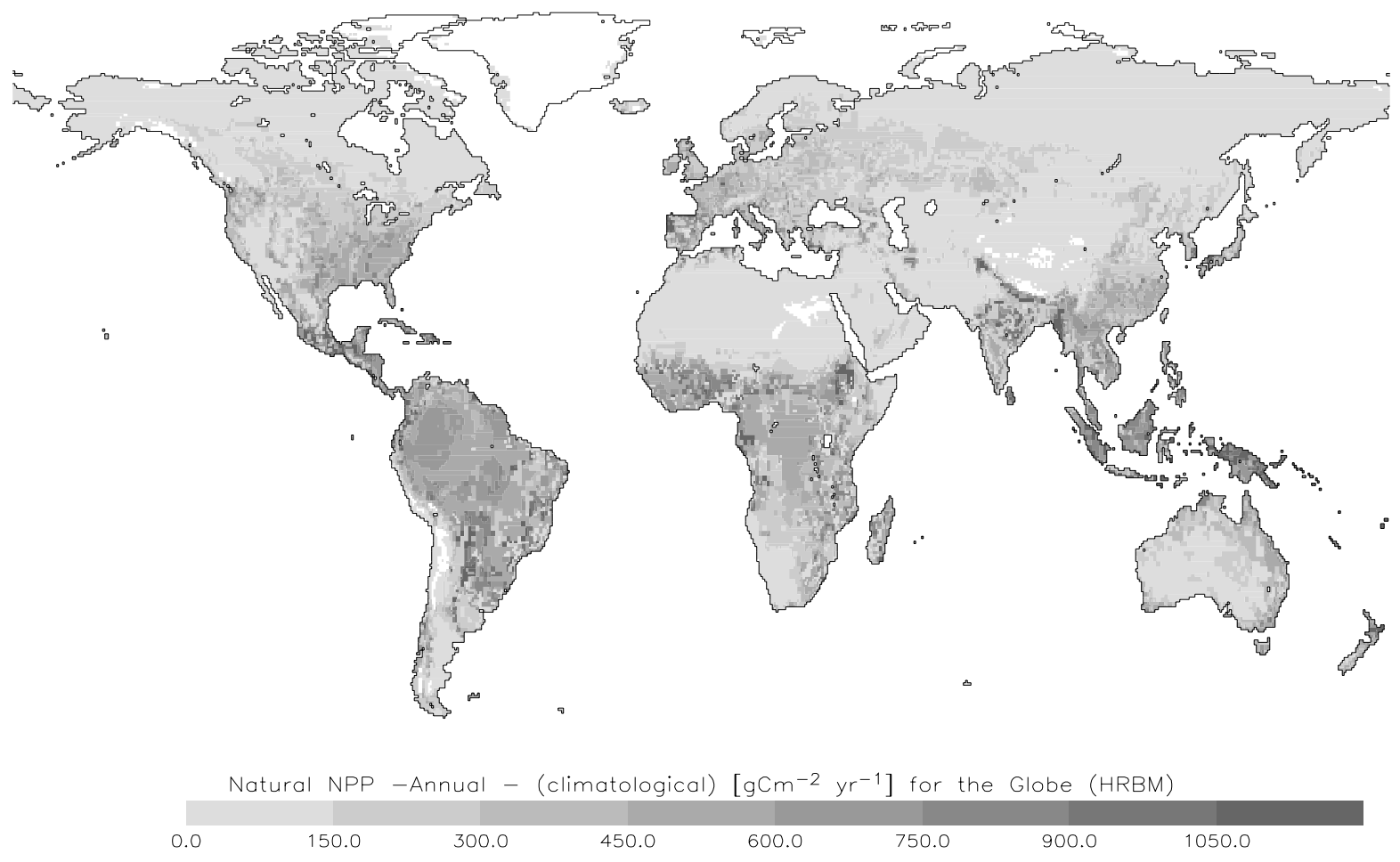

Figure 9: Annual potential natural NPP from the HRBM run in 1980.

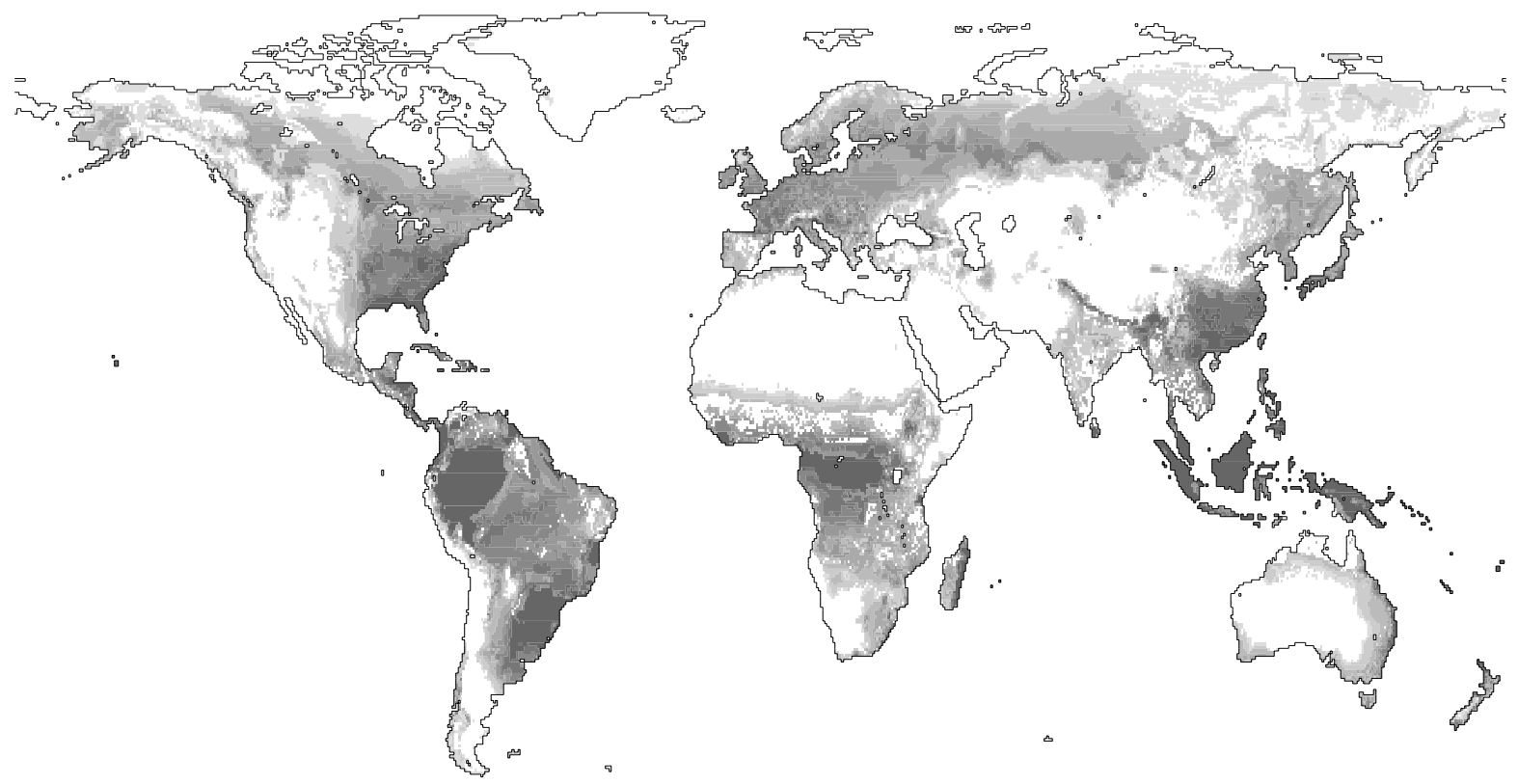

Natural NPP - Annual - (climatological) $\left[\mathrm{gCm}^{-2} \mathrm{yr}^{-1}\right]$ for the Globe (New model)

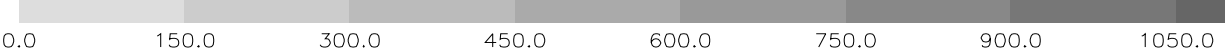

Figure 10: Annual potential natural NPP resulting from the new model. 


\subsection{Global net seasonal fluxes}

As a final validation test we investigated the seasonal cycle of the atmospheric $\mathrm{CO}_{2}-$ concentration generated by the net biospheric $\mathrm{CO}_{2}$-fluxes of the new model using the atmospheric transport model TM2 (Heimann and Keeling 1989, Heimann 1995). The transport model was forced with the observed winds of the year 1986 and was run for four years to obtain a cyclo-stationary state. In the northern hemisphere the biospheric $\mathrm{CO}_{2}$-signal dominates the annual cycles of atmospheric $\mathrm{CO}_{2}$, whereas in the southern hemisphere oceanic exchange fluxes and seasonally varying transport processes are also important (Heimann et al. 1989). Therefore we show the results of the simulated annual cycles of atmospheric $\mathrm{CO}_{2}$ together with observations for six northern hemispheric stations in Fig. 11.

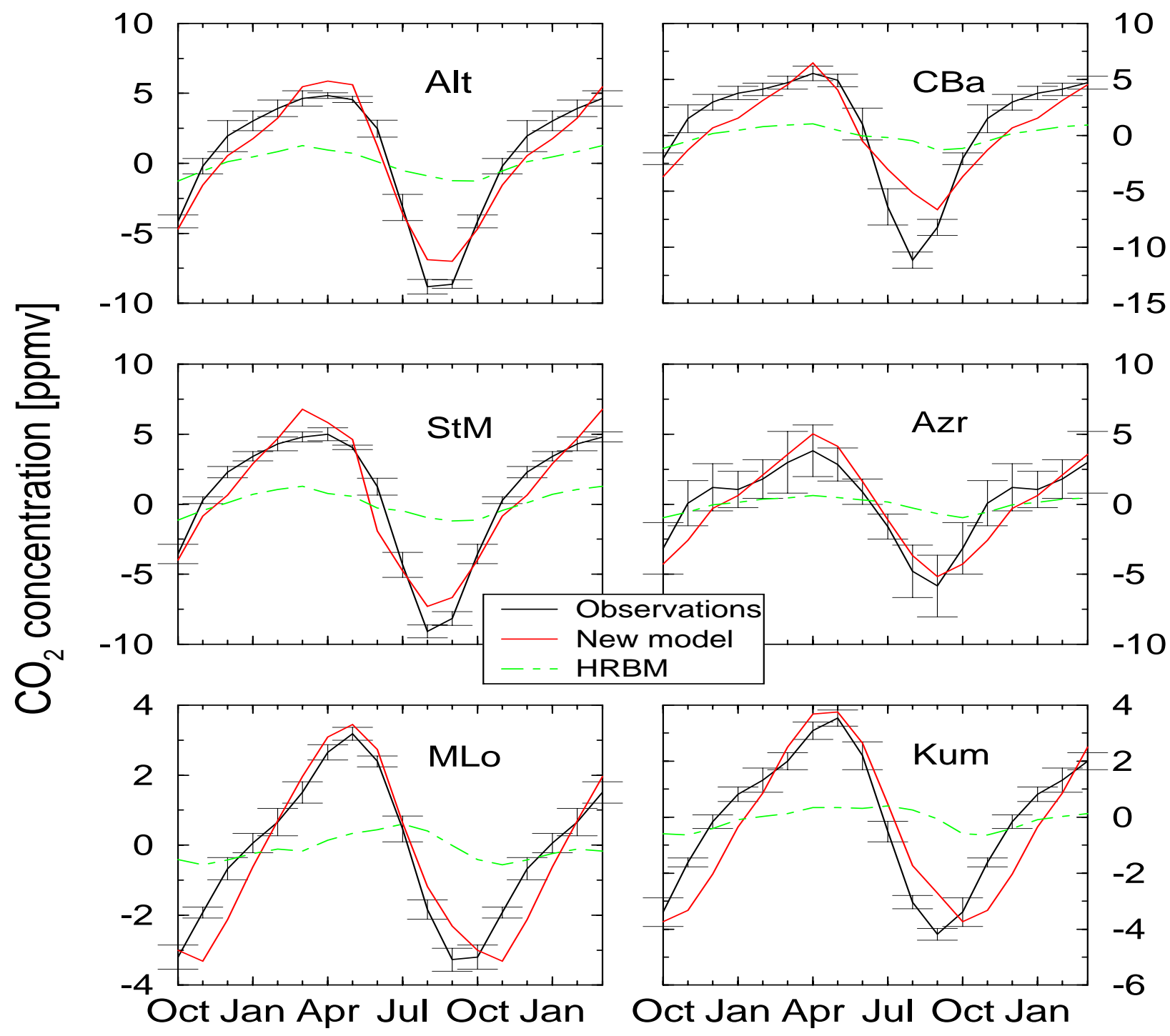

Figure 11: Seasonal cycles of atmospheric $\mathrm{CO}_{2}$-concentration resulting from the biospheric $\mathrm{CO}_{2}$ fluxes of the new model and the standard HRBM (dashed curve) compared to observations (black solid line) at northern hemispheric stations. (Abbreviations symbolize: AltAlert, 82.50N, 62.33W; CBa- Cold Bay, 55.02N, 162.72W; StMOcean station M, 66.00N, 2.00E; Azr- Azores, 38.75N, 27.08W; MLo- Mauna Loa, 19.53N, 155.58W; and Kum- Cape Kumukahi, $19.52 \mathrm{~N}, 154.82 \mathrm{~W})$. 
The amplitude and phase of the annual cycle resulting from the new NPP model match the observations (black solid line) quite well in contrast to the annual cycle generated by the standard HRBM (dashed line) which is not pronounced enough, indicating too strong an overlap of the times of net primary production and heterotrophic respiration.

Thus our NPP and phenology modules simulate a strong drawdown of the atmospheric $\mathrm{CO}_{2}$-concentration in northern spring by allowing for a rapid budburst which is supported by the stored assimilates. 


\section{Conclusions}

New formulations for simulating the phenological course of vegetation and NPP were developed and implemented as submodels in the HRBM. The new submodels were designed as relatively independent units facilitating their exchange with other terrestrial carbon cycle models. Both submodels are based on mechanistic descriptions of plant physiology and are forced with climate data.

First evaluations indicate that the simulated NPP of forests appears realistic. However, NPP of grass dominated biomes is greatly underestimated and the scheme fails completely in hot desert environments.

A comparison with observed seasonal cycles of the atmospheric $\mathrm{CO}_{2}$-concentration shows that the new model reproduces the seasonal cycle much more realistically than the standard HRBM. This indicates that the phenology scheme gives a reasonable timing of NPP versus litter decay during different times of the year since it is the difference of these two $\mathrm{CO}_{2}$ fluxes, i.e. the net flux, which is the quantity contributing to the seasonal atmospheric $\mathrm{CO}_{2}$ variation. These results indicate that an appropriate simulation of the local seasonal cycles of $\mathrm{CO}_{2}$ exchanges based on climate driven physiologically orientated phenology schemes seems feasible.

We limited ourselves to here to the modelling of natural vegetation although today large parts of the vegetated land area are anthropogenically influenced. However large fractions of the global NPP are still produced by natural or relatively undisturbed forest areas in the tropics and the boreal zone. Simulations of agricultural systems would require additional components to account for example for fertilizer input or planting techniques. Conceptually our model represents a component of a more general model framework which would distinguish between natural and other vegetation types.

For simulations of the global terrestrial carbon dynamics on interannual times scales the new model is not yet suitable. The NPP module must be improved to include the climate sensitive processes of photosynthesis on a more biochemical-physiological basis and growth respiration needs to be included. For longer simulations the soil module needs to be improved too, such that eventually the storage and release of carbon by soils and wetlands can be accounted for.

For projections in the more distant future, possibly with drastically elevated atmospheric $\mathrm{CO}_{2}$-concentrations, the fixed ratios of woody to herbaceous biomass as well as aboveground to belowground biomass have to be replaced with an ecophysiological approach of biomass allocation. Fixed fractions are not appropriate as for example root/shoot ratios of many plants change under elevated $\mathrm{CO}_{2}-$ concentrations (Oechel and Strain 1985). However until now no conclusive assessment of the effects of an elevated $\mathrm{CO}_{2}$-concentration on natural ecosystems can be made. Finally, a complete description of the terrestrial biospheric carbon cycle should include succession and migration processes. However, such an integrated description on landscape to continental scale of these processes for prediction purposes is presently not known. The incorporation of all these processes in a global terrestrial carbon cycle model represents a big challenge for the modelling community in the next decade.

Acknowledgements: We thank Colin Prentice for invaluable help in particular with the physiological part of the model, Gerd Esser for his friendly support of the HRBM and the access to his database, Frank Mack for the generous supply of datasets of various biological parameters, Martin Claussen, Gerd Esser, Georg Hoffmann and Colin Prentice for comments on an early version of the manuscript and three anonymous reviewers for their very helpful suggestions.

This work was supported in part by the EC projects EPOC-CT90-0017 and EV5V-CT920120 . 


\section{References}

Amthor JS (1984) The role of maintenance respiration in plant growth. Plant Cell Environ $7: 561-569$

Cosby BJ, Hornberger, GM, Clapp, RB, Ginn, TR (1984) A statistical exploration of the relationships of soil moisture characteristics to the physical properties of soils. Water Resour Res 20(6):682-690

Desjardins, RL, Schuepp, PH, MacPherson, JI, Buckley, DJ (1992) Spatial and temporal variations of the fluxes of Carbon dioxide and sensible and latent heat over the FIFE site. J Geophys Res 97 (D7):18467-18476

Esser G, Aselman I, Lieth H (1982) Modelling the carbon reservoir in the system compartment "litter". In: Degens and Kempe (eds) Transport of Carbon and Minerals in Major World Rivers, Part 1. Mitt. Geol-Paläontol Inst Univ Hamburg, SCOPE/UNEP Sonderband 52 , p $39-58$

Esser, G (1984) The significance of biospheric carbon pools and fluxes for atmospheric $\mathrm{CO}_{2}$ : A proposed model structure. Prog Biometeorol 3:253-294

Esser, G (1991) Osnabrück Biosphere Model: construction, structure, results. In: Esser, G, Overdieck, D (eds) Modern Ecology: Basic and Applied Aspects. Amsterdam, Elsevier Sci. Publ., 844 pp

Esser, G, Hoffstadt, J, Mack, F, Wittenberg, U (1994). High Resolution Biosphere Model Version 3.00.00 - Dokumentation. Mitteilungen aus dem Institut für Pflanzenökologie der Justus Liebig Universität Giessen, Heft 2, 68pp

Evans, JR (1989) Photosynthesis and nitrogen relationships in leaves of $\mathrm{C}_{3}$ plants. Oecologia $78: 9-19$

Gallo, KP (1992) Experimental global vegetation index from AVHRR utilizing pre-launch calibration, cloud and sun-angle screening. Digital Data. National Oceanic and Atmospheric Administration, National Geophysical Data Center, Boulder/Colorado

Knorr, W, Heimann, M (1994) Sensitivity study of land biosphere $\mathrm{CO}_{2}$-exchange through an atmospheric tracer transport model using satellite-derived vegetation index data. Report of the Max-Planck-Institute of Meteorology, no. 127, Hamburg

Knorr, W, Heimann, M (1995) Impact of drought stress and other factors on seasonal land biosphere $\mathrm{CO} 2$ exchange studied through an atmospheric tracer transport model. Tellus, in press.

Heimann, M (1995) The TM2 transport model, Hamburg/Germany: Deutsches Klimarechenzentrum Technical Report, forthcoming

Heimann, M, Keeling, CD (1989) A three-dimensional model of atmospheric $\mathrm{CO}_{2}$ transport based on observed winds: 2. Model description and simulated tracer experiments. In: Peterson DH (ed) Aspects of Climate Variability in the Pacific and the Western Americas, American Geophysical Union, Washington, DC, p 165-236 
Heimann, M, Keeling, CD, Tucker, DJ (1989) A three-dimensional model of atmospheric $\mathrm{CO}_{2}$ transport based on observed winds: 3. Seasonal cycle and synoptic time scale variations. In: Peterson, DH (ed) Aspects of climate variability in the Pacific and the Western Americas, American Geophysical Union, Washington, DC, p 277-303

Janecek, A, Benderoth, G, Lüdeke, MKB., Kindermann, J, Kohlmaier, GH (1989) Model of the seasonal and perennial carbon dynamics in deciduous-type forests controlled by climatic variables. Eco Mod 49:101-124

Jarvis, PG, MacNaughton, KG (1986) Stomatal control of transpiration: scaling up from leaf to region. Advances in Ecological Research 15:1-49

Johnson, FH, Eyring, H, Polissar, MJ (1954) The kinematic basis of molecular biology. Wiley, New York

Landsberg, JJ (1986) Physiological ecology of forest production. Academic Press, Orlando/Florida

Larcher, W (1984) Ökologie der Pflanzen. $4^{\text {th }}$ ed., Eugen Ulmer, Stuttgart

Lerch, G (1991) Pflanzenökologie. Akademie Verlag, Berlin

Leemans, R, Cramer, WP (1991) The IIASA database for mean monthly values of temperature, precipitation, and cloudiness on a global terrestrial Grid. IIASA Research Report RR-91-18

Lieth, H (1975) Modeling the primary productivity of the World. In: Lieth, H, Whittaker, RH (eds) Primary Productivity of the Biosphere. Ecol. Studies 14, Springer, Berlin Heidelberg New York, p 237-264

Linacre, ET (1986) Estimating the net radiation flux. Agric Meteorol 5:49-63.

Lommen, PW, Schwintzer, CR, Yocum, CS, Gates, DM (1971) A model describing photosynthesis in terms of gas diffusion and enzyme kinetics. Planta 98:195-220

Lüdeke, MKB, Dönges, S, Otto, RD, Kindermann, J, Badeck, F-W, Ramge, P, Jäkel, U, Kohlmaier, GH (1995) Responses in NPP and carbon stores of the northern biomes to a $\mathrm{CO}_{2}$-induced climatic change, as evaluated by the Frankfurt biosphere model (FBM). Tellus 47B(1/2):191-205

Mack, F (1994) The influence of vegetation fires on the global carbon cycle. Ph. D. thesis, Inst. for Plant Ecology, Justus-Liebig-Universität, Giessen, Germany

Medina, E, Klinge, H (1983) Productivity of tropical forests and tropical woodlands. In: Lange, OL et al. (eds) Physiological Plant Ecology IV, Springer, Berlin, p 281-303

Mitchell, JFB, Manabe, S, Meleshko, V, Tojioka T (1990) Equilibrium Climate Change - and its implications for the future. In: Houghton et al. (eds) Climate Change - The IPCC Scientific Assessment, Cambridge University Press, Cambridge, p 131-172

Monsi, M, Saeki, T, (1953) über den Lichtfaktor in Pflanzengesellschaften und seine Bedeutung für die Stoffproduktion. Jap J Bot 14:22-52 
Murray, MB, Cannell, MGR, Smith, RI (1989) Date of budburst of fifteen tree species in Britain following climate warming. Journal of Applied Ecology 26:693-700

Oechel, WC, Strain, BR (1985) Native species response to increased atmospheric carbon dioxide concentration. In: Strain, BR, Cure, JD (eds) Direct effects of increasing carbon dioxide on vegetation. DOE report ER-0236, Washington, DC, p 117-154

Olson, JS, Watts, JA, Allison, LJ (1983) Carbon in live vegetation of major world ecosystems. Report DOE/NBB-0037 for US Dept. of Energy, Carb. Diox. Res. Div., Washington, $\mathrm{DC}$

Prentice, IC, Cramer, W, Harrison, SP, Monserud, RA, Solomon, AM (1992) A global biome model based on plant physiology and dominance, soil properties and climate. Journal of Biogeography 19:117-134

Prentice, IC, Sykes, MT, Cramer, W (1993) A simulation model for the transient effects of climate change on forest landscapes. Eco Mod 65:51-70

Raich, JW, Rastetter, EB, Melillo, JM, Kicklighter, DW, Steudler, PA, Peterson, BJ, Grace, AL, Moore III, B, Vörösmarty, CS (1991) Potential net primary productivity in South America: Application of a global model. Ecological Applications 1(4):399-429

Ryan, MG (1989) Sapwood volume for three subalpine conifers: predictive equations and ecological implications. Can J For Res 19:1397-1401

Ryan, MG (1991) Effects of climate change on plant respiration. Ecol appl 1(2):157-167

Ryan, MG, Linder, S, Vose, JM, Hubbard, RM. (1993) Dark respiration in Pinaceae. Ecol Bull 43

Shinozaki, K, Yoda, K, Hozumi, K, Kira, T (1964) A quantitative analysis of plant form The Pipe Model Theory I. Basic analyses. Jap J Ecol 14 (3):97-104

Sprugel, DG, Ryan, MG, Brooks, JR, Vogt, KA, Martin, TA (1995) Respiration from the organ level to the stand. In: Smith, WK, Hinckley, TM (eds) Resource physiology of Conifers: Acquisition, Allocation and Utilization, Academic, San Diego, p255-299

Verma, SB, Kim, J, Clement, RJ (1992) Momentum, water vapour, and Carbon dioxide exchange at a centrally located Prairie site during FIFE. J Geophys Res 97 (D7):1862918640

Wardlow, IF (1990) The control of carbon partioning in plants. New Phytol 116:341-381

Waring, RH, Schlesinger, WH (1985) Forest ecosystems, concepts and management. Academic Press, Orlando/Florida

Webb, RS, Rosenzweig, CE, Levine, ER (1992) A global data set of soil particle size properties. In: Global Ecosystems Database Version 1.0: Disc A on CD-ROM. NOAA National Geophysical Data Center (first published 1991) Boulder, CO

Whittaker, RH, Likens, GE (1973) Carbon in the biota. In: Woodwell, GM Pecan, EV (eds) Carbon and the Biosphere, Proceedings of the 24th Brookhaven Symposium in Biology, Upton, New York, NTIS, Springfield Virginia 
Whittaker, RH, Marks, PL (1975) Methods of assessing terrestrial productivity. In: Lieth, H, Whittaker, RH (eds) Primary productivity of the Biosphere, Ecol Studies 14, Springer, Berlin, Heidelberg, New York, p 55-118 


\section{A Model quantities}

\section{A.1 State variables}

$p a-$ Content of assimilate pool, $\left[\mathrm{gCm}^{-2}\right]$

$p h-$ Content of living herbaceous biomass pool, $\left[\mathrm{gCm}^{-2}\right]$

$p w$ - Content of living woody biomass pool, $\left[\mathrm{gCm}^{-2}\right]$

lh- Content of herbaceous litter pool, $\left[\mathrm{gCm}^{-2}\right]$

$l w-$ Content of woody litter pool, $\left[\mathrm{gCm}^{-2}\right]$

soc- Content of soil organic carbon pool, $\left[\mathrm{gCm}^{-2}\right]$

$s w-$ Soil water $[\mathrm{mm}]$

\section{A.2 Other variables}

$A(z, t)$ - Instantaneous gross assimilation of the leaves at height $\mathrm{z},\left[\mu \mathrm{molCO}_{2} \mathrm{~m}^{-2} \mathrm{sec}^{-1}\right]$

$B$ - Bole height, not explicitly required

$G P P_{s t d}-$ Unstressed daily gross production, $\left[\mu \mathrm{molCO}_{2} \mathrm{~m}^{-2} \mathrm{~d}^{-1}\right]$

$H$ - Stand height, $H=20\left(0.001 p w^{0.521}\right)^{0.4},[\mathrm{~m}]$

$I(z, t)$ - Instantaneous downward PAR at time $\mathrm{t}$ and height $\mathrm{z}$ in the canopy, $\left[\frac{\mu \mathrm{E}}{\mathrm{m}^{2} \sec }\right]$

$I_{0}(t)$ - Instantaneous downward not reflected PAR at top of canopy and time t, $\left[\frac{\mu \mathrm{E}}{\mathrm{m}^{2} \sec }\right]$

$I_{a b}(z, t)$ - Instantaneous absorbed PAR at time $\mathrm{t}$ and height $\mathrm{z}$ in the canopy, $\left[\frac{\mu \mathrm{E}}{\mathrm{m}^{2} \mathrm{sec}}\right]$

$L(z)$ - Accumulated leaf area above height $\mathrm{z},\left[\mathrm{m}^{2}\right]$

$L A I-$ Leaf area index, $L A I=S L A^{*} \cdot p h,\left[\mathrm{~m}^{2} \mathrm{~m}^{-2}\right]$

$L A I_{\max }-$ Maximal LAI for current timestep, $L A I_{\max }=\min \left(L A I_{n p p}, L A I_{\text {veg }}\right),\left[\mathrm{m}^{2} \mathrm{~m}^{-2}\right]$

$L A I_{n p p}-$ Zero of $\frac{d N P P}{d L A I}$ in the current timestep, $\left[\mathrm{m}^{2} \mathrm{~m}^{-2}\right]$

$L A I_{v e g}$ - Maximal structually possible LAI, $L A I_{v e g}=S L A^{*} \cdot f h \cdot p t o t,\left[\mathrm{~m}^{2} \mathrm{~m}^{-2}\right]$

$P_{\max }(z)-$ Maximal assimilation rate of the leaves at height $\mathrm{z}, P_{\max }(z)=A_{\max } e^{-k s_{L}(H-z)}$, $\left[\mu \mathrm{molCO}_{2} \mathrm{~m}^{-2} \mathrm{sec}^{-1}\right]$

$R_{l}-$ Instantaneous outgoing long wave radiation, $\left[\mathrm{Wm}^{-2}\right]$

$R_{n}$ - Instantaneous net radiation, $\left[\mathrm{Wm}^{-2}\right]$

$R_{s}$ - Instantaneous, not reflected short wave radiation, $\left[\mathrm{Wm}^{-2}\right]$

$R_{s t d}-$ Daily plant respiration at $\mathrm{T}=\mathrm{T}_{\mathrm{ref}},\left[\frac{\mu \mathrm{molCO}_{2}}{\mathrm{~m}^{2} \mathrm{~d}}\right]$

$R h z-$ Leaf plus fine root respiration rate for height $\mathrm{z}$ at $\mathrm{T}=\mathrm{T}_{\mathrm{ref}}, R h_{z}=0.1 P_{\max }(z),\left[\frac{\mu \mathrm{mol}}{\mathrm{m}^{2} \sec }\right]$ 
$R l_{\max }-$ Sun leaf respiration rate at temperature $\mathrm{T}=\mathrm{T}_{\mathrm{ref}}, R l_{\max }=0.1 A_{\max },\left[\frac{\mu \mathrm{mol}}{\mathrm{m}^{2} \mathrm{sec}}\right]$

Rs- Sapwood respiration rate at temperature $\mathrm{T}=\mathrm{T}_{\mathrm{ref}}, R s=\frac{100}{m} R l_{\max },\left[\frac{\mu \mathrm{molCO}_{2}}{\mathrm{~m}^{3} \mathrm{sec}}\right]$

$\operatorname{Rt}(\mathrm{z})-$ Respiration for height $\mathrm{z}$ at temperature $\mathrm{T}=\mathrm{T}_{\mathrm{ref}}$, eq. $20,\left[\frac{\mu \mathrm{molCO}}{\mathrm{m}^{2} \mathrm{sec}}\right]$

$S A I(z)$ - Sapwood cross seqtional area at height $\mathrm{z}, S A I(z)=\epsilon L(z),\left[\mathrm{m}^{2} \mathrm{~m}^{-2}\right]$

$\mathrm{SLA}^{*}-$ Reduced specific leaf area, $\mathrm{SLA}^{*}=\frac{1}{1+\mathrm{rs}} \mathrm{SLA},\left[\mathrm{m}^{2}(\mathrm{gC})^{-1}\right]$

$S V I$ - Sapwood volume index, $S V I=\epsilon L A I \cdot H,\left[\frac{\mathrm{m}^{3}}{\mathrm{~m}^{2}}\right]$

$T_{\text {opt }}-$ Optimal assimilation temperature, $\mathrm{T}_{\mathrm{opt}}=\frac{2}{5}\left(\mathrm{~T}_{\min }+1.5 \mathrm{~T}_{\max }\right),\left[{ }^{\circ} \mathrm{C}\right]$

$T_{\text {ref }}$ - Reference temperature for respiration, $T_{\text {ref }}=T_{\text {opt }},\left[{ }^{\circ} \mathrm{C}\right]$

$d h h-$ Mean diameter at breast height, $d b h=0.001 p w^{0.521},[\mathrm{~m}]$

$f w-$ Maximal fraction of woody biomass, $\mathrm{fw}=1-\mathrm{fh}$

$h_{2}$ - Fraction of assimilate pool allocated daily to herbaceous biomass

$h_{3}-$ Fraction of assimilate pool allocated daily to woody biomass

$l d r_{x}$ - daily rates of heterotrophic respiration for herbaceous and woody material as well as $\operatorname{SOC}(\mathrm{x}=\mathrm{h}, \mathrm{w}$ and $\mathrm{s}$ respectively)

ptot - Total "living" carbon, $\mathrm{ptot}=\mathrm{pa}+\mathrm{ph}+\mathrm{pw},\left[\mathrm{gCm}^{-2}\right]$

$s_{L}-$ Leaf density, $s_{L}=\frac{L A I}{H-B},\left[\mathrm{~m}^{2} \mathrm{~m}^{-3}\right]$

z - independent height variable

$\Phi_{C}-\mathrm{CO}_{2}$ index for assimilation

$\Phi_{D}-$ Drought index for assimilation

$\Phi_{T}-$ Temperature index for assimilation

$\mu_{T}-$ Temperature index for plant respiration

\section{A.3 Parameters}

$A_{\max }-$ Maximal assimilation rate of sun leaves, $\left[\mu \mathrm{molCO}{ }_{2} \mathrm{~m}^{-2} \mathrm{sec}^{-1}\right]$

SLA- Specific leaf area, $\left[\mathrm{m}^{2}(\mathrm{gC})^{-1}\right]$

$T_{\max }-$ Maximal assimilation temperature, $\left[{ }^{\circ} \mathrm{C}\right]$

$T_{\text {min }}-$ Minimal assimilation temperature, $\left[{ }^{\circ} \mathrm{C}\right]$

a,b,c- Parameters for equation (26)

$e^{*}-$ Factor for converting $\left[\frac{\mu \mathrm{E}}{\mathrm{m}^{2} \mathrm{sec}}\right]$ in $\left[\frac{\mathrm{W}}{\mathrm{m}^{2}}\right], e^{*}=0.22,\left[\mathrm{MJ} \mathrm{E} \mathrm{E}^{-1}\right]$

$f h$ - Maximal fraction of herbaceous biomass of total plant mass 
$k$ - Extinction coefficient for Beer's law formulation of light extinction in the canopy

$l a-$ Mean leaf age, [yr]

$l w$ - Mean stand age, $[\mathrm{yr}]$

$r s-$ Root/shoot ratio.

,- $\mathrm{CO}_{2}$-compensation point, $,=80,[\mathrm{ppmv}]$

$\beta$ - Plant short wave albedo

$\epsilon-$ Ratio of sapwood cross sectional area to leaf area index, $\left[\mathrm{m}^{2} \mathrm{~m}^{-2} \cdot 10^{-4}\right]$

$\phi-$ Quantum yield efficiency, $0.07,\left[\mathrm{molE}^{-1}\right]$

$\rho$ - Activation energy for respiration divided by the gas constant, $[\mathrm{K}]$ 


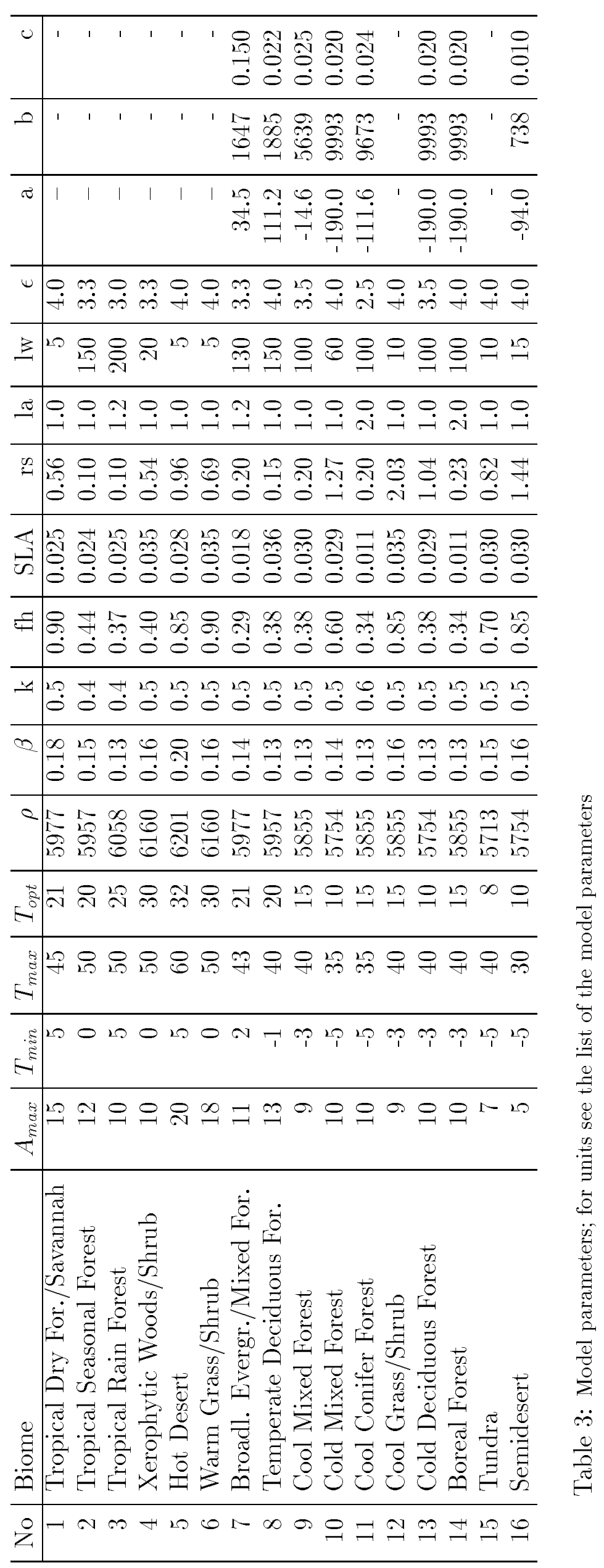

